\title{
EL CRECIMIENTO DE LAS EXPORTACIONES Y EL DESEMPEÑO DE LA PRODUCTIVIDAD EN LA INDUSTRIA MANUFACTURERA EN MEXICO
}

\author{
Juan Pablo Graf Noriega
}

(El autor es Investigador de la Dirección de Estudios Económicos. Agradezco a los miembros de esta Dirección por sus comentarios y a Emilio Bertrán y Ana Luisa Saavedra por su colaboración en la preparación de este documento. El contenido del documento es responsabilidad del autor y no representa el punto de vista de Banco de México.)

Documento de Investigación No. 9605

Noviembre, 1996

Banco de México

Dirección General de Investigación Económica 


\title{
EL CRECIMIENTO DE LAS EXPORTACIONES Y EL DESEMPEÑO DE LA PRODUCTIVIDAD EN LA INDUSTRIA MANUFACTURERA EN MÉXICO
}

\author{
Juan Pablo Graf Noriega \\ Noviembre, 1996 \\ Documento de Investigación No. 9605 \\ Dirección General de Investigación Económica, Banco de México
}

\section{RESUMEN}

Este trabajo presenta un análisis del crecimiento de las exportaciones de la industria manufacturera de México durante el periodo 1970-1984. La industria manufacturera se desagrega en 20 sectores y se busca establecer si distintos factores explican el crecimiento de las exportaciones de cada sector. En la primera parte se revisan los modelos más frecuentemente utilizados en la literatura para este propósito. Se resume la discusión sobre la importancia que tienen los factores de oferta y de demanda en el crecimiento de las exportaciones. La consideración de estos modelos, junto con la disponibilidad de la información, sirven para formular una función para los volúmenes de exportación que se evalúa en la parte siguiente.

Se asume que los volúmenes de exportación dependen del tipo de cambio real, de la capacidad de oferta doméstica y de la demanda extranjera. Se consideran dos indicadores para el tipo de cambio real: los precios relativos y los costos unitarios relativos de la mano de obra. Estos últimos son seleccionados como el indicador del tipo de cambio real que se utiliza en el estudio, lo cual se justifica por las posibilidades que este indicador ofrece para el análisis de los determinantes de las exportaciones.

Las variaciones de los costos unitarios de la mano de obra de las industrias manufactureras se comparan y se encuentran importantes contrastes. Adicionalmente, dichas variaciones se descomponen en cambios de la productividad relativa de la mano de obra y de los salarios relativos. Las variaciones de estos dos componentes igualmente muestran diferencias importantes para las industrias.

El análisis de regresión que se presenta sirve para clasificar las industrias en términos de los factores que explican el crecimiento de las exportaciones. Se muestra que el crecimiento de las exportaciones de algunas industrias se explica por el cambio de los salarios, en otros casos por los cambios de la productividad, y para el resto de la industrias, por el impulso de la demanda extranjera 0 por la capacidad de oferta. La clasificación de las industrias que se presenta en el trabajo representa una contribución importante al entendimiento sobre las diferentes explicaciones del crecimiento de las exportaciones en México. 


\section{Introducción.}

En años recientes el crecimiento de las exportaciones se ha convertido en una variable de suma importancia para evaluar el desempeño de la economía Mexicana. Las exportaciones son importantes no sólo por las fuentes de empleos e ingresos que generan, sino además porque brindan al país una fuente importante de divisas que son necesarias para solventar los pagos por bienes y servicios que México requiere del exterior.

En este trabajo se estudia el crecimiento de las exportaciones de México para el período 1970-1994. D ada la creciente importancia de la industria manufacturera como generadora de exportaciones, nos concentramos en el desempeño de esta industria. Más aún, dado que al interior de esta misma industria la contribución de los distintos sectores a este proceso ha sido distinta, presentamos un análisis del crecimiento de la exportaciones de 20 sectores de esta industria. El objetivo es determinar si distintos factores explican el crecimiento de las exportaciones de cada sector manufacturero.

Este análisis es importante desde la perspectiva de la política económica ya que permite identificar qué factores influyen en el comportamiento de las exportaciones de cada sector, y de esta manera establecer en que sectores la acción de la política debe enfocarse para mejorar el desempeño exportador.

En la primera parte del documento se presenta el modelo para el análisis del volumen de exportaciones. Siendo el tipo de cambio real una variable de importancia en este modelo, en la siguiente sección se examina la evolución de esta variable para cada una de las industrias manufactureras mexicanas. Los resultados econométricos son presentados en la tercera sección, seguidos por un análisis de respuesta de las exportaciones a variaciones del tipo de cambio real. En la última sección se presentan las conclusiones del trabajo.

\section{La ecuación para la determinación de las cantidades.}

En esta sección se presenta el modelo que se utiliza para evaluar los determinantes de las exportaciones de los distintos sectores manufactureros. Primeramente se hace un breve resumen de la literatura relacionada con este tema, y posteriormente se introduce la ecuación de estimación.

\subsection{La importancia de la oferta y la demanda por exportaciones.}

Desde hace muchos años ha existido un debate acerca de si el crecimiento de las exportaciones de los países en desarrollo ha estado limitado por la expansión de la demanda mundial, o si las condiciones domésticas y las políticas en estos países son las que explican el comportamiento de sus exportaciones. Goldstein y Khan (1985) presentan un resumen de esta literatura y señalan que "en general los estudios empíricos de series de tiempo sobre las ecuaciones de importaciones y exportaciones no han modelado formalmente el lado de la oferta". Ciertamente, hasta antes de mediados de los 70s era común asumir que únicamente los factores de demanda eran importantes en la determinación de las exportaciones de un país en vías de desarrollo. Se creía que estos países eran capaces de ajustar sus cantidades ofrecidas en respuesta a las fluctuaciones de la demanda mundial sin alterar sus precios (elasticidad-precio infinita de la oferta). Sin embargo la evidencia empírica en contra de esta argumentación fue aumentando. Por ejemplo, Goldstein y Khan (1978) mostraron que la elasticidad precio de la demanda por exportaciones tendía a ser sistemáticamente mayor cuando se estimaba en un marco econométrico de ecuaciones simultáneas que cuando era obtenida de una sola ecuación de demanda. Para mediados de esa década era comúnmente aceptado que junto con la demanda extranjera, los factores del lado de la oferta tienen una gran importancia en la determinación de las exportaciones. 
La contribución más reciente a esta literatura surgió en torno al estudio de las exportaciones de Hong Kong, a partir del trabajo de Riedel (1988), y las críticas que sobre este trabajo se presentaron en Nyuyen (1989), Muscatelli \&. al .(1994) y Muscatelli (1991). (Para una discusión similar sobre el caso de las exportaciones manufactureras del Reino Unido, ver Landesmann y Snell (1989) y la crítica de Holly y Weade (1991); y para el caso de Grecia y Corea, véase Balassa, et. al. (1989). Athukolara y Riedel (1991) presentan un análisis similar a Riedel (1988), para el caso de las exportaciones Coreanas de maquinaria y equipo.) D esde el punto de vista de Riedel el extraordinario crecimiento de las exportaciones de Hong Kong se debió a las políticas aplicadas por el gobierno de ese país, que creó los incentivos adecuados para la exportación. Por el lado de la demanda, Riedel no encuentra ninguna restricción al crecimiento de las exportaciones porque Hong Kong es un competidor "pequeño" en los mercados mundiales que enfrenta una demanda infinitamente elástica por sus productos. Además, el autor concluye que los precios de exportación de este país se encuentran únicamente determinados por los precios internacionales.

Por el contrario, haciendo uso del mismo conjunto de información estadística, Muscatelli (1994) encuentra por el lado de la demanada una baja elasticidad precio y una alta elasticidad ingreso para este mismo país. Dicho de otra manera, aunado a las variables que determinan la oferta de las exportaciones, la demanda mundial también ha jugado un papel importante en la expansión de las exportaciones.

Ambos puntos de vista son congruentes con el hecho de que los precios de las exportaciones de Hong Kong no han disminuido con respecto a los precios de sus competidores. Sin embargo, estas visiones son claramente incompatibles, especialmente con respecto al papel del ingreso extranjero en la determinación de las exportaciones manufactureras para un país en desarrollo.

Muscatelli ofrece una explicación de estos puntos de vista contradictorios, basada en el modelo del ciclo de producto formalizado más recientemente por Krugman (1989). El argumento principal es el siguiente:

"Los países cuyo crecimiento económico es más rápido expanden su participación en los mercados mundiales, no por medio de la reducción de los precios relativos de sus bienes sino a través de la expansión del rango de bienes que producen al crecer sus economías. Lo que nosotros medimos como exportaciones e importaciones no son realmente un conjunto fijo de bienes, sino agregados cuyas definiciones cambian a través del tiempo a medida que más bienes se incluyen en la lista." (Krugman, 1989, pp. 1039).

En términos del debate sobre las exportaciones de Hong Kong, la controversia se puede resumir en los siguientes términos. D esde el punto de vista de Riedel, las exportaciones de Hong Kong son sólo una pequeña proporción de las manufacturas mundiales y este país es tomador de precios; además los productos de Hong Kong no están diferenciados. D esde el punto de vista de Muscatelli et. al., la expansión doméstica de Hong Kong ha llevado a la producción de mayor variedad de manufacturas que los mercados mundiales han demandado. Muscatelli (1994) concluye:

"es imposible para una economía pequeña incrementar sus exportaciones expandiendo su capacidad productiva sin recurrir a la competencia vía precios u otros factores no relacionados con los precios. Esta interpretación difiere marcadamente del mundo de la competencia perfecta-país pequeño [postulado por Riedel], donde todos los países en desarrollo pueden mejorar su desempeño, sin importar su estructura de producción y su posición en la escalera de la calidad." (Muscatelli, 1994, p.1417).

Todo lo anterior implica que desde las perspectivas teórica y empírica es difícil creer que las exportaciones manufactureras de un país en desarrollo no se ven afectadas por la demanda mundial (Las barreras comerciales que los exportadores de los países en vías de desarrollo enfrentan constituyen evidencia adicional que también cuestiona la hipótesis del país "pequeño". ¿Cómo puede 
sostenerse el argumento de la elasticidad infinita de la demanda en la presencia de estas prácticas comerciales? Véase a este respecto, el Reporte de Comercio y Desarrollo del UNCTAD de 1991 donde se enlistan los casos en que las exportaciones mexicanas hacia E.U.A. enfrentaron medidas no arancelarias en 1990.). Los factores de oferta y demanda deben ser considerados. El modelo más popular para conducir la investigación en esta línea es el modelo de ecuaciones simultáneas para precios y cantidades. Sin embargo, este no es el único marco en el que los determinantes de las cantidades y los precios de exportación pueden ser analizados. En su estudio sobre las exportaciones manufactureras de G ran Bretaña, Winters (1981) ofrece algunos fundamentos teóricos para asumir que los precios son fijados antes e independientemente de las cantidades, pero las cantidades sí dependen de los precios. En su opinión es razonable pensar que los precios se establecen antes de que se lleven a cabo las transacciones. Este es el caso cuando los mercados de exportación están caracterizados por estructuras oligopólicas, en las cuales las funciones de oferta y demanda no se comportan adecuadamente. Winters cita evidencia empírica para apoyar este argumento. D e esta manera, en el modelo de Winters se formula una ecuación para los precios de las exportaciones, asumiendo que las cantidades no tienen efecto sobre ellos, y se presenta otra ecuación para las cantidades en donde los precios de las exportaciones sí se consideran como un argumento explicativo.

Diversas pruebas estadísticas han sido propuestas en la literatura para poder establecer la conveniencia del uso del modelo de ecuaciones simultáneas (oferta y demanda), o el modelo recursivo, o simplemente un modelo de oferta para cada caso empírico. Para llevar a cabo estas pruebas se necesita información estadística sobre los precios de exportación. En el caso de México no se cuenta con información de este tipo. Como se explica en Graf (1995), donde se hace un análisis de la determinación de los precios de exportación para el caso de México basado en valores unitarios, la limitada evidencia que se tiene al respecto, sugiere que aunque los precios pueden estar influenciados por los costos de producción, parece razonable asumir que los precios se encuentran fundamentalmente determinados por los precios internacionales (aproximados por los precios al productor en los E.U.A.). Lo anterior no implica necesariamente que las exportaciones no se vean afectadas por las variaciones del ingreso mundial, como lo postula la hipótesis del país pequeño.

En esta parte podemos concluir que la literatura teórica y empírica sobre las elasticidades precio e ingreso de las exportaciones tiende a coincidir en que tanto los factores de la oferta como los de la demanda son importantes. Dado que no podemos aplicar los modelos que consideran explícitamente la demanda y la oferta, por la falta de información de los precios, hemos decidido analizar las cantidades de exportación mediante una sola ecuación que incorpora tanto elementos de oferta como de demanda.

\subsection{Un modelo para el análisis de las cantidades.}

En esta sección se presenta un modelo para el estudio de las cantidades, que puede ser interpretado como una ecuación para las cantidades una vez que los precios han sido fijados (el modelo recursivo), o bien como la forma reducida de un modelo de oferta y de demanda. Las cantidades en ambos casos son una función de factores de "oferta" y "demanda". Se postula inicialmente que el tipo de cambio real, la capacidad de oferta para exportar, la presión de la demanda doméstica y la demanda extranjera son los principales determinantes de las exportaciones.

El objetivo de este análisis es establecer si distintos factores afectan las exportaciones de cada industria manufacturera en un modelo de series de tiempo. No se consideran aquí todos los factores que desde un punto de vista teórico o analítico podrían afectar a las exportaciones, ya que no hay datos disponibles para algunos factores para el periodo de tiempo bajo estudio (1970-1994), o para el nivel de agregación usado en este trabajo. Este es el caso, por ejemplo, de la construcción de infraestructura básica, como carreteras y puertos, o servicios de información para los exportadores, 0 las políticas de promoción del gobierno. 


\subsubsection{Tipo de cambio real.}

Se considera que el tipo de cambio real es un elemento clave de la competitividad de un país. Los precios relativos y los costos unitarios relativos de la mano de obra son dos indicadores de esta variable comúnmente citados en la literatura. Los precios relativos se definen como:

$$
R P_{i t}=W P_{i t}-P D_{i t}-E_{i t} \ldots \text { (1) }
$$

donde: $\mathrm{WP}_{\mathrm{it}}$ es el (logaritmo del) índice de precios en el extranjero para la industria "i" en el periodo "t" que el productor obtiene si decide exportar, $\mathrm{PD}_{\text {it }}$ es el (logaritmo del) índice de precios doméstico para los mismos bienes expresado en moneda nacional (pesos) y $E_{t}$ es el (logaritmo del) índice del tipo de cambio (unidades de moneda doméstica por unidad de moneda extranjera). $\mathrm{RP}_{\text {it }}$ entra en la ecuación de cantidad de exportaciones como una medida del costo de oportunidad de vender en el mercado doméstico. Se asume implícitamente que el costo de producir bienes para los mercados doméstico y extranjero es similar. Ahora bien, si el índice de precios doméstico y el costo unitario de producción se mueven juntos en el tiempo, RP sirve para medir la rentabilidad absoluta de las exportaciones. Holly y Wade (1991), por ejemplo, incluyeron tanto a $\mathrm{RP}_{\text {it }}$ como un indicador de la rentabilidad absoluta en su de oferta para el Reino Unido. Esto no es posible en el presente estudio porque no contamos con los datos de los costos unitarios totales.

Los costos unitarios de la mano de obra (ULC, por sus siglas en inglés) en la industria manufacturera son los sueldos y salarios pagados a los trabajadores a precios corrientes divididos por el producto bruto a precios constantes (Fagerberg, 1988, p.355). Los costos unitarios relativos de la mano de obra (RULC) son el ULC promedio de los países que son socios comerciales (representados en este caso por E.U.A.) dividido por el ULC de México convertido a moneda extranjera (dólares):

$$
R U L C_{i t}=U L C_{i t}{ }^{\text {EUA }}-\left(U L C_{i t}{ }^{\text {MEX }}-E_{t}\right) \ldots
$$

La presencia de RULC en una ecuación de las cantidades exportadas puede justificarse como una medida alternativa de la competitividad. Se asume que los precios de otros insumos de la producción son similares para los distintos países, o que se mueven en la misma dirección; y que por lo tanto, los costos laborales determinan la competitividad de las empresas (Enoch 1978, p.186). En el caso de México este indicador es relevante para aquellas empresas que importan la mayoría de los insumos para la producción de bienes exportables y que sólo añaden valor agregado a las mercancías por concepto de la mano de obra. Un régimen abierto al comercio internacional permite a las empresas domésticas adquirir los insumos. Aún si existieran restricciones al comercio internacional, las empresas pueden adquirir dichos insumos con la condición de que éstas exporten sus productos. Este parece ser un instrumento importante de política que los países en vías de desarrollo usan con frecuencia. En el caso de México, los exportadores han recibido este tratamiento al menos desde 1983, aunque sólo se formalizó hasta 1985 en el Programa de Importación Temporal para la Exportación (PITEX). Se puede argumentar que otros costos son diferentes en México y en el extranjero (por ejemplo, el precio de la energía). Sin embargo, esto no necesariamente implica que no se deba de utilizar RULC en la ecuación de cantidad, si durante el periodo de análisis los otros costos medidos en dólares se mueven en la misma dirección que los precios internacionales.

¿Qué indicador se debe utilizar en el presente caso? (Para una discusión similar sobre el caso de Inglaterra, ver Enoch (1978) y Anderton y Dunnet (1987).) RP y RULC son utilizados alternativamente en la ecuación que explica las exportaciones porque miden el mismo fenómeno: la competitividad.

\subsubsection{Capacidad de oferta para exportar.}

Para un nivel dado de precios relativos, las empresas manufactureras pueden incrementar sus exportaciones a medida que crezca su capacidad de producción. Los argumentos para incluir esta variable están relacionados con economías de escala y la evolución de los productos. Existe evidencia de que los países que han crecido mas rápido durante el periodo de la posguerra, han 
incrementado sus exportaciones más rápido que los países que han crecido menos. (El mejor ejemplo es el comportamiento relativo de Japón, por un lado, y el de Inglaterra y los Estados Unidos por el otro. La bibliogragía sobre este tema es extensa. Ver, por ejemplo, Thirlwall (1979), Krugman (1989b). Para la experiencia de países en desarrollo, ver Muscatelli, et al. (1994).) Para captar estos fenómenos, usualmente se incluye un indicador de capacidad en una función de oferta para exportaciones. Los indicadores más comunes encontrados en la literatura para esta variable son: producto manufacturero actual, su tendencia (ver ecuación (3) abajo) o simplemente una tendencia lineal del tiempo. (Winters (1981), por ejemplo, utiliza una trayectoria de tiempo en la ecuación de cantidad.) En este trabajo, el producto manufacturero actual y su trayectoria se utilizan alternativamente. Se muestra que no existen diferencias importantes en los resultados obtenidos usando ambos indicadores. A prion, se rechaza la hipótesis de que las exportaciones y el producto para cada industria manufacturera se determinan simultáneamente, en virtud de que las exportaciones constituyen una pequeña proporción de las ventas totales.

\subsubsection{La presión de la demanda doméstica.}

Este es un factor importante que afecta a las exportaciones y que usualmente no es tomado en cuenta. (Moran (1988) argumenta que "la omisión de la demanda agregada puede justificarse si el país no consume los bienes que exporta, o si la producción se caracteriza por rendimientos constantes a escala(p. 323)". Estos supuestos no parecen razonables en el presente caso. Balassa et. al. (1989) agrega a estas dos razones la posibilidad de que los precios relativos capturen los efectos de los cambios en la demanda doméstica.) Hay dos problemas relacionados para modelar este efecto. Primero, la selección del indicador relevante de la variable, y segundo, la correlación con los precios relativos.

Dunlevy (1980) presenta un breve resumen de algunos artículos que han tratado de modelar la variable de presión a la demanda. Este autor analiza las diferentes aproximaciones comúnmente propuestas para la presión de la demanda doméstica, y emplea en su estudio el nivel de utilización de la capacidad instalada. La utilización de la capacidad se define como el cociente entre la producción observada (IMP) y la capacidad (CAP). En la ausencia de un indicador de capacidad, como por ejemplo, el acervo de capital, esta variable es comúnmente obtenida ajustando la producción actual a una trayectoria lineal:

$$
\text { CAP: IMP }=\alpha \mathrm{e}^{\beta t} \ldots(3)
$$

donde y se obtienen de acuerdo con: IMP $=\alpha+\beta t+u_{t}$; esto es, tomando logaritmos de la ecuación (3). La utilización de capacidad es por lo tanto IMP/ CAP. Este es un indicador común de la presión de la demanda doméstica en la literatura. Este procedimiento puede ser criticado porque asume que la tasa de crecimiento de la capacidad es constante durante el periodo. Algunas veces una tendencia cuadrática es también incluída en la ecuación (3). Así lo hace, por ejemplo, Cohen (1993) en su estudio de México. Al utilizar una tendencia cuadrática, se obtiene una tasa de crecimiento decreciente después de algún periodo, lo cual resulta ser una descripción más precisa del caso mexicano. Lo que es importante remarcar es que los resultados dependerán de una medición correcta de la capacidad para cada industria manufacturera considerada en este análisis.

Finalmente se decidió no incorporar esta variable, en virtud de que el problema de medición podría influir decisivamente a los resultados. Lo anterior no necesariamente significa que los efectos de las variaciones de la demanda doméstica no sean considerados en la ecuación de cantidad. Como se dijo antes, si la presión de la demanda doméstica se refleja en el crecimiento de los precios domésticos de las manufacturas sobre sus contrapartes internacionales (medidos en la misma moneda), su efecto ya está tomado en cuenta por el término del precio relativo en la ecuación de cantidad. (Los precios relativos pueden considerarse como un indicador del tipo de cambio real como se explicó en la sección anterior. Algunos modelos macroeconómicos para los países en desarrollo formalizan la idea de que existe una relación inversa entre el tipo de cambio real y la demanda doméstica. Ver por 
ejemplo Krugman y Taylor (1978) y Buffie (1984)). O tros autores han procedido de manera similar por la misma razón. (Ver, por ejemplo, Balassa, et. al. (1989), Moran (1988) y Riveros (1989), y para el caso de México, Salas y Alfaro (1992).)

\subsubsection{Demanda extranjera.}

También puede esperarse que las cantidades exportadas se incrementen con la demanda extranjera. $\mathrm{Si}$ los precios relativos indican que la exportación es más rentable que vender en el mercado doméstico, un incremento de la demanda externa va a desviar las ventas domésticas, para un nivel dado de producto. Podría considerarse que el caso de un "país pequeño" se aplica a México, por lo que la demanda extranjera no debería entrar en la ecuación de cantidad. Pero como se argumentó antes, este no es el caso si las exportaciones son bienes diferenciables y si el comportamiento de tomar los precios de los competidores es una práctica común.

Generalmente se utiliza alguno de los siguientes dos indicadores para la demanda extranjera en una ecuación de exportaciones agregadas: el ingreso, aproximado por el PIB, o las importaciones. En un análisis desagregado las importaciones del extranjero para bienes específicos (para los cuales existen datos disponibles) dan una mejor aproximación de la demanda extranjera para productos mexicanos, que los indicadores agregados del ingreso, tal como el gasto en consumo en bienes durables y no durables ya que estos no se encuentran disponibles para cada tipo de producto de exportación.

La ecuación que se utiliza para la evaluación econométrica de las exportaciones es la siguiente:

$$
X_{i t}=\delta_{0}+\delta_{1} R E R_{i t}+\delta_{2} M^{M P} P_{i t}+\delta_{3} M S_{i t}+u_{i} \ldots(4)
$$

donde (todas las variables están en logaritmos):

- $\quad X_{\text {itt }}$ representa el índice del volumen de las exportaciones para la industria "i" en el año "t". Se obtiene dividiendo el valor de las exportaciones por el índice de precios al productor en los Estados Unidos $\left(\mathrm{WP}_{\mathrm{it}}\right)$.

- $\quad \mathrm{RER}_{\mathrm{it}}$ es el índice del tipo de cambio real. Dos indicadores de esta variable se usan en el estudio. Primero, el deflactor implícito del producto relativo, $\mathrm{RP}_{\mathrm{it}}$ (E.U.A./ México) y los costos unitarios relativos de la mano de obra, RULC $_{\text {it }}$ (E.U.A. / Mexico). Un incremento de este índice representa una depreciación del tipo de cambio real.

- $\quad$ IMP $_{\text {it }}$ es el índice de la capacidad de oferta de las manufacturas, aproximada por el índice de la producción manufacturera a precios constantes.

- MUS $_{\text {it }}$ es el índice de las importaciones de los Estados Unidos a precios constantes (el valor de las importaciones entre $\mathrm{WP}_{\mathrm{it}}$.

D ado que se toma el logaritmo de las variables, las d's son elasticidades, y esperamos que todas ellas sean positivas. El subíndice "i" representa a las industrias manufactureras a tres dígitos de agregación de la Clasificación Internacional Industrial Uniforme de actividades económicas (CIIU, en adelante), que equivale a 20 industrias, y "t" se refiere a observaciones anuales. En el apéndice II se explica en detalle la construcción de las variables y se presentan las fuentes de información.

Por dos razones se toman datos de E.U.A. como aproximación a los datos del "extranjero". Primero, porque la participación de los E.U.A. en las exportaciones de manufacturas es más del $80 \%$ en el agregado. Y, segundo, por el alto costo que implicaría construir un indicador ponderado de acuerdo con la participación de cada socio comercial para cada industria. 


\section{Análisis preliminar: el tipo de cambio real y la competitividad.}

Como se mencionó en la sección anterior, el tipo de cambio real se considera como un componente importante de la competitividad de los países, junto con algunos otros factores no relacionados con los precios. Los dos indicadores del tipo de cambio real que se utilizan en el presente estudio son los precios al productor relativos y los costos unitarios relativos de la mano de obra.

¿Cuál de estos indicadores debe de ser usado para evaluar el grado de respuesta de los exportadores a las variaciones del tipo de cambio real? Antes de comentar este punto, es importante notar que existe una alta correlación entre RP y RULC. En el cuadro 1 se presenta el coeficiente de correlación entre esta dos variables para cada sector manufacturero durante el periodo 1970-1984 y para dos subperiodos: 1970-1982 y 1983-1994. 
Cuadro 1

Coeficientes de correlación entre precios relativos (RP) y costos unitarios relativos de la mano de obra (RULC), 19701994.

\begin{tabular}{|c|c|c|c|c|}
\hline & Industrias CIIU & $1970-1994$ & $1970-1982$ & 1983-1994 \\
\hline 3 & Total manufacturero & 0.874 & 0.719 & 0.899 \\
\hline $311-312$ & Alimentos & 0.787 & 0.801 & 0.914 \\
\hline 313 & Bebidas & 0.845 & 0.809 & 0.876 \\
\hline $321-322$ & Textiles y prendas de vestir & 0.761 & 0.918 & 0.937 \\
\hline 323 & Cuero y sus productos & 0.670 & 0.689 & 0.199 \\
\hline 324 & Calzado & 0.813 & 0.846 & 0.970 \\
\hline 33 & Madera y sus productos & 0.603 & 0.857 & 0.434 \\
\hline 341 & Papel y sus productos & 0.914 & 0.909 & 0.614 \\
\hline 342 & Imprentas y editoriales & 0.323 & 0.522 & 0.785 \\
\hline $351-352$ & Productos químicos industriales & 0.184 & -0.716 & 0.781 \\
\hline $353-354$ & Refinería de petróleo y sus derivados & 0.414 & 0.609 & 0.659 \\
\hline 355 & Productos de hule & 0.156 & 0.207 & 0.842 \\
\hline 356 & Productos de plástico & 0.359 & 0.625 & 0.737 \\
\hline 361 & Objetos de barro, loza y porcelana & 0.720 & 0.640 & 0.897 \\
\hline 362 & Productos de vidrio & 0.414 & 0.952 & 0.864 \\
\hline 369 & Cemento y otros min. no metálicos & 0.476 & 0.441 & 0.264 \\
\hline 371 & Hierro y acero & 0.698 & 0.767 & 0.769 \\
\hline $381-382$ & Maquinaria y productos metálicos & 0.584 & 0.792 & 0.534 \\
\hline 383 & Maquinaria eléctrica & 0.811 & 0.507 & 0.951 \\
\hline 384 & Equipo de transporte & 0.573 & -0.318 & 0.856 \\
\hline 385 & Equipo profesional y científico & -0.235 & -0.846 & 0.540 \\
\hline 39 & Otros productos manufacturados & 0.010 & 0.829 & 0.761 \\
\hline
\end{tabular}


La mayoría de los coeficientes son altos y positivos, lo que sugiere que existe una correlación marcada entre las variables, aunque hay importantes excepciones. Para algunas industrias la correlación es alta en los dos subperiodos comparada con la existente a lo largo del periodo. Este es el caso, por ejemplo, de la industria del vidrio (CIIU 362). Para ilustrar este punto, en la gráfica 1 se presentan las series de tiempo de RP y RULC de esta industria.

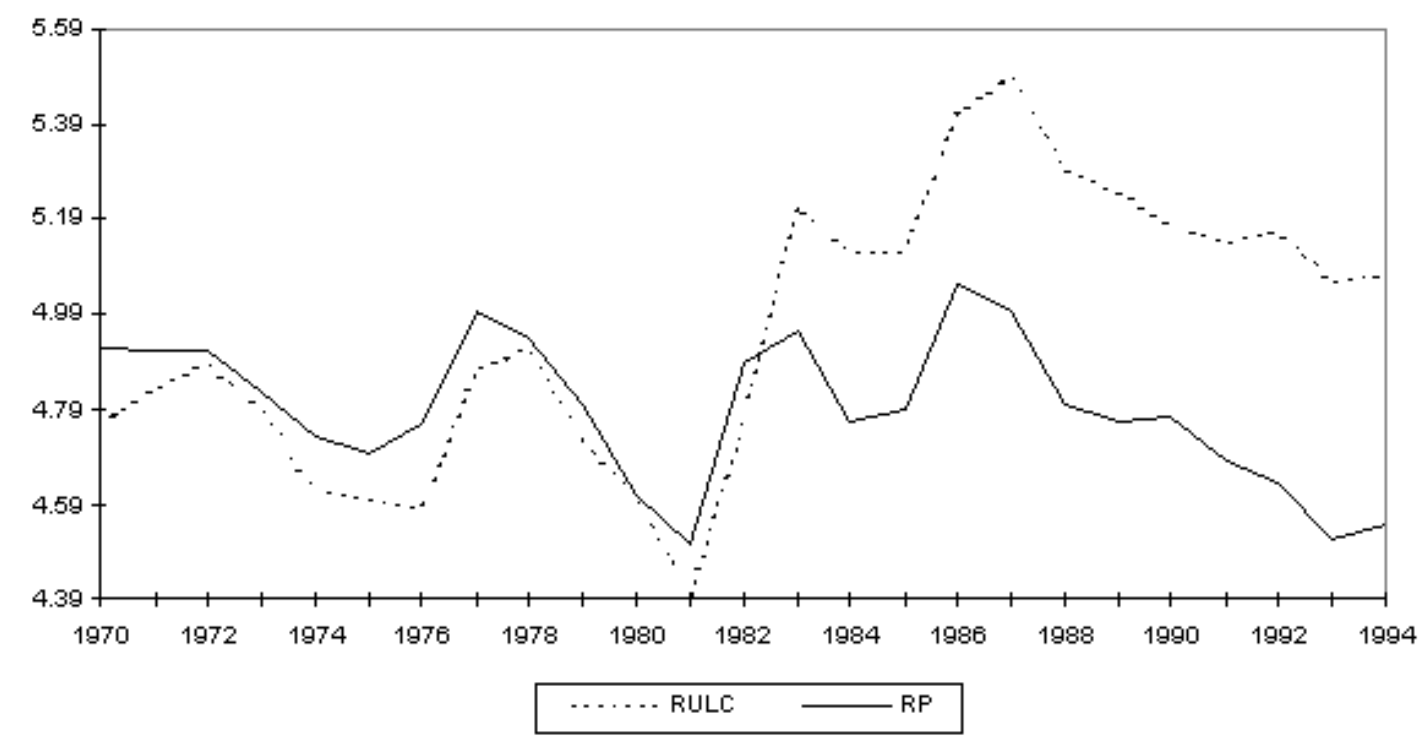

Nótese que la relación entre ambos indicadores es muy estrecha entre 1970 y 1982, así como entre 1983 y 1994. Durante 1983 la variable RULC observó una fuerte depreciación (que se explica principalmente por la contracción de los salarios mexicanos medidos en dólares), pero RP no se depreció tanto como lo hizo RULC. Lo anterior explica porqué el coeficiente de correlación para todo el periodo es menor que el coeficiente para ambos subperiodos. Hay otras industrias para las cuales el patrón de correlación es similar al CIIU-362, como puede verse en el cuadro 1.

Este análisis nos lleva a dos observaciones importantes para resto del trabajo. Primero, como los datos para RULC parecen ser más confiables (ver el apéndice de los datos al final del artículo), este indicador será utilizado como el del tipo de cambio real en el análisis econométrico de las cantidades exportadas. Adicionalmente, las regresiones se corrieron también con RP como indicador del tipo de cambio real, para aquellas industrias que tienen un coeficiente de correlación bajo entre los indicadores del tipo de cambio real. (Como se verá más adelante, el uso de RULC enriquece el análisis de los determinantes del crecimiento de las exportaciones.)

Segundo, como las condiciones económicas cambiaron a partir de 1982-1983, se pueden obtener diferentes determinantes para las exportaciones entre subperiodos. La fuerte depreciación de RULC durante 1983 y el cambio gradual de la política comercial, que permitió a los exportadores importar insumos sin restricciones para el proceso de exportación, le dieron a las empresas mexicanas una posición más competitiva en los mercados mundiales.

Antes de pasar al análisis de la regresión esta sección continúa con un análisis preliminar de los movimientos RULC en el sector manufacturero. 


\subsection{RULC en el sector manufacturero}

RULC es por lo tanto la variable utilizada en el análisis como el indicador del tipo de cambio real. La evolución de esta variable durante el periodo de análisis es el centro de esta sección. En general, el comportamiento de la variable es muy similar para los sectores de las manufacturas. La gráfica 1, que muestra el índice de RULC y RP para la industria del vidrio, puede utilizarse para brindar una primera impresión de este comportamiento.

Como puede verse, el comportamiento del tipo de cambio real ha estado caracterizado por fuertes depreciaciones casi cada seis años $(1977,1982-1983,1987)$. (El último episodio de este proceso es la devaluación de diciembre de 1994; la depreciación del tipo de cambio real se refleja en 1995.) Después de una pequeña depreciación entre 1970 y 1972, RULC se apreció hasta 1976. La devaluación de septiembre de 1976 provocó una fuerte depreciación del tipo de cambio real, la que se reflejó más claramente en 1977. D espués, a partir de 1978, hubo una apreciación que duró hasta 1981. La crisis de 1982-1983 llevó a un fuerte ajuste del tipo de cambio nominal y al consecuente ajuste del tipo de cambio real. D urante los siguientes dos años se produjo apreciación, seguida de una depreciación en 86-87. De ahí en adelante, RULC muestra una apreciación, con algunas excepciones, que termina con la devaluación del peso en diciembre de 1994.

La trayectoria seguida por RULC para CIIU-362 muestra un patrón común con el resto de las industrias manufactureras, pero existen algunas diferencias importantes. Para dar una idea del contraste existente, el siguiente cuadro presenta el índice de RULC para cada industria manufacturera. RULC fue construída tomando como año base 1980, lo que no implica que el nivel de RULC en 1980 estuviera en un nivel de equilibrio. (Comparar los niveles de costos unitarios laborales entre países está fuera del alcance de este trabajo. Hooper y Vrankovich (1995) proponen una metodología para realizar dicha comparación.) Los valores de RULC en el cuadro fueron obtenidos promediando observaciones alrededor del año para eliminar fluctuaciones de corto plazo. O bviamente, los cálculos son muy sensibles al año elegido. El objetivo es mostrar las diferencias que existen entre los diversos sectores de las manufacturas. 
Cuadro 2

Niveles de RULC, 1980=100 1/.Promedio de tres observaciones alrededor del af10

\begin{tabular}{|c|c|c|c|c|}
\hline & CIIU & 1971 & 1981 & 1993 \\
\hline 3 & Total manufacturero & 115.8 & 91.8 & 136.1 \\
\hline 311 & Alimentos & 131.1 & 95.8 & 117.8 \\
\hline 313 & Bebidas & 101.5 & 92.3 & 130.1 \\
\hline 321 & Textiles y prendas de vestir & 140.5 & 92.2 & 132.7 \\
\hline 323 & Cuero y sus productos & 131.9 & 93.5 & 173.8 \\
\hline 324 & Calzado & 115.3 & 100.4 & 122.4 \\
\hline 33 & Madera y sus productos & 123.5 & 82.7 & 102.8 \\
\hline 341 & Papel y sus productos & 96.3 & 91.4 & 152.1 \\
\hline 342 & Imprentas y editoriales & 126.1 & 96.7 & 159.5 \\
\hline 351 & Productos quedmicos industriales & 165.4 & 94.4 & 137.9 \\
\hline 353 & Refinereda de petrf3leo y sus derivados & 83.1 & 104.4 & 138.2 \\
\hline 355 & Productos de hule & 106.2 & 82.2 & 146.1 \\
\hline 356 & Productos ple1sticos & 133.5 & 102.4 & 194.0 \\
\hline 361 & Objetos de barro, loza y porcelana & 118.4 & 93.5 & 140.4 \\
\hline 362 & Productos de vidrio & 124.6 & 86.0 & 163.3 \\
\hline 369 & Cemento y otros min. No mete 1 licos & 120.3 & 91.6 & 236.3 \\
\hline 371 & Hierro y acero & 103.4 & 89.9 & 162.6 \\
\hline 381 & Maquinaria y productos mete 1 licos & 115.1 & 88.9 & 79.2 \\
\hline 383 & Maquinaria ele9ctrica & 84.6 & 96.4 & 131.3 \\
\hline 384 & Equipo de transporte & 89.1 & 93.6 & 214.4 \\
\hline 385 & Equipo profesional y cientedfico & 58.5 & 109.0 & 374.9 \\
\hline 39 & Otros productos manufacturados & 149.6 & 99.6 & 152.9 \\
\hline
\end{tabular}


1/ RULC son costos unitarios relativos de la mano de obra. Un incremento en el edndice implica un tipo de cambio real me1s competitivo.

El cuadro 2 muestra que el comportamiento de las industrias manufactureras no ha sido homoge9neo. Si comparamos el nivel de RULC para el inicio del periodo (1970-1972), nf3tese que la industria quedmica y otras industrias manufactureras (CIIU-351 y 39, respectivamente) tienen los me1s altos niveles con respecto a 1980. En otras palabras, la posicif3n de RULC se deteriorf3 me1s que el resto hasta 1980-1982. En el otro extremo, para el equipo profesional y cientedfico (385), la madera y sus productos (341), la maquinaria ele9ctrica (383) y el equipo de transporte (384), se observan niveles de RULC me1s parecidos a los de 1980-1982, lo que quiere decir que RULC no se deteriorf3 tanto en estos casos. Con respecto a los niveles de RULC al final del periodo considerado (1992-1994), algunas industrias muestran un crecimiento significativo de la variable, especialmente el equipo profesional, el cemento y otros minerales no metellicos, ased como el equipo de transporte (CIIU 385, 369, 384, respectivamente). La maquinaria, el calzado, las bebidas y la industria textil y del vestido (CIIU-381, 324,313, 321) en el otro extremo, muestran una depreciacif3n considerable. Por lo tanto, aunque la trayectoria de RULC es similar en las manufacturas, es posible detectar diferencias, y el objetivo es encontrar si las mismas son fatiles para explicar el crecimiento de las exportaciones en las manufacturas.

\subsection{Descomposicif3n de RULC: productividad y salarios.}

Recordemos que RULC son los costos unitarios relativos de la mano de obra de E.U.A. / Me9xico:

$$
R U L C_{i t}=\frac{U L C_{i t}^{E . U . A}}{U L C \$_{i t}^{i M E X}}
$$

donde los subedndices "i" y "t" se refieren respectivamente a las industrias de CIIU y a los af1os. Los costos unitarios de la mano de obra (ULC) esteln definidos como el edndice de sueldos y salarios pagados a precios corrientes $\left(W_{i}\right)$ dividido por el edndice de producto bruto a precios constantes $\left(\mathrm{O}_{\mathrm{it}}\right)$. (D e acuerdo con Fagerberg, 1988, p.355. Es necesario recalcar que en este trabajo los costos unitarios de la mano de obra de E.U.A. se toman como una aproximacif3n del ULC extranjero, y que lo que pretende es conocer cuelles son los efectos de los cambios de RULC en el crecimiento de las exportaciones, no del nivel de RULC.) Sin embargo, el pago de salarios y el producto de una industria pueden variar con el empleo. Si el objetivo es comparar costos unitarios, es mejor normalizar los salarios y el producto con el edndice de empleo. Entonces, el ULC de un paeds puede expresarse como la relacif3n de sueldos y salarios $\left(\mathrm{W}_{\mathrm{it}}\right)$ por trabajador $\left(\mathrm{L}_{\mathrm{it}}\right)$ dividida por el producto $\left(\mathrm{O}_{\mathrm{it}}\right)$ por trabajador $\left(\mathrm{L}_{\mathrm{it}}\right)$ :

$$
=\frac{W_{i t}}{O_{i t}}=\frac{\frac{W_{i t}}{L_{i t}}}{\frac{O_{i t}}{L_{i t}}}
$$

donde:

$\mathrm{W}_{\mathrm{it}}, \mathrm{O}_{\mathrm{it}} \mathrm{y} \mathrm{L}_{\mathrm{it}}$ son respectivamente los edndices de sueldos y salarios pagados (en df3lares), el producto en te9rminos constantes, y el empleo.

Sustituyendo la ecuacif3n (6) en la ecuacif3n (5) y despue9s de cierta manipulacif3n algebraica, RULC puede expresarse como la diferencia (si tomamos el logaritmo de las variables) entre el salario relativo (EUA/ Me9xico) por trabajador (RWL) y el producto relativo (EUA/Me9xico) por trabajador (ROL). 


$$
\operatorname{LN}\left(R U L C_{i t}\right)=L N\left(R W L_{i t}\right)-\operatorname{LN}\left(R O L_{i t}\right) \ldots(7)
$$

En otras palabras, Me9xico puede obtener un incremento de la competitividad si los salarios por trabajador (en df3lares) crecen menos que en E.U.A. o si el producto por trabajador crece me1s relpido que en E.U.A. De esta manera, existen dos formas posibles de mejorar la competitividad, medida por RULC. En te9rminos de bienestar, un paeds deseareda ver mejorada su posicif3n de competitividad expandiendo el producto por trabajador mels relpido que sus competidores, en lugar de reducir el salario por trabajador en relacif3n con el de otros paedses (por ejemplo, con una devaluacif3n de su moneda).

Esta distincif3n es muy importante cuando la aplicamos a diferentes industrias manufactureras.(Casar (1991) propone esta idea en su estudio de la "ventaja comparativa revelada" de las manufacturas en Me9xico.) Para cada una de ellas se obtuvieron los cambios en RULC durante el periodo de ane1lisis y despue9s se descompusieron en cambios en RWL y en ROL. Para hacerlo, nf3tese que si la ecuacif3n (7) se cumple en el af10 " $t$ ", tambie9n se cumple en "t+1" (las variables este1n en logaritmos aunque los te9rminos "LN" fueron suprimidos para simplificar). Entonces:

$$
\left(R L_{i, t+r}-R U L C_{i, t}\right)=\left(R W L_{i, t r}-R W L_{i, t}\right)-\left(R O L_{i, t+r}-R O L_{i, t}\right) \ldots(8)
$$

En el cuadro 3, se presentan los cambios de RULC y sus componentes para cada industria. 
Cuadro 3

Cambio de RULC y sus componentes

\begin{tabular}{|c|c|c|c|c|c|c|c|}
\hline \multicolumn{2}{|r|}{ CIIU } & \multicolumn{3}{|c|}{ 70-72 A 80-82 } & \multicolumn{3}{|c|}{ 80-82 A 92-94 } \\
\hline & & RULC 1/ & RWL 2/ & ROL 3/ & RULC 1/ & RWL 2/ & ROL 3/ \\
\hline 3 & Total manufacturero & $-23 \%$ & $-32 \%$ & $-8 \%$ & $39 \%$ & $41 \%$ & $2 \%$ \\
\hline 311 & Alimentos & $-31 \%$ & $-30 \%$ & $1 \%$ & $29 \%$ & $26 \%$ & $-3 \%$ \\
\hline 313 & Bebidas & $-10 \%$ & $8 \%$ & $18 \%$ & $34 \%$ & $38 \%$ & $4 \%$ \\
\hline 321 & Textiles y prendas de vestir & $-42 \%$ & $-41 \%$ & $1 \%$ & $36 \%$ & $60 \%$ & $24 \%$ \\
\hline 323 & Cuero y sus productos & $-34 \%$ & $-43 \%$ & $-8 \%$ & $62 \%$ & $59 \%$ & $-3 \%$ \\
\hline 324 & Calzado & $-14 \%$ & $-46 \%$ & $-32 \%$ & $20 \%$ & $52 \%$ & $32 \%$ \\
\hline 33 & Madera y sus productos & $-40 \%$ & $-51 \%$ & $-11 \%$ & $22 \%$ & $47 \%$ & $25 \%$ \\
\hline 341 & Papel y sus productos & $-5 \%$ & $-17 \%$ & $-12 \%$ & $51 \%$ & $44 \%$ & $-7 \%$ \\
\hline 342 & Imprentas y editoriales & $-26 \%$ & $-31 \%$ & $-4 \%$ & $50 \%$ & $45 \%$ & $-5 \%$ \\
\hline 351 & Productos quedmicos industriales & $-56 \%$ & $-31 \%$ & $26 \%$ & $38 \%$ & $41 \%$ & $4 \%$ \\
\hline 353 & Ref. de petrf3leo y derivados & $23 \%$ & $-23 \%$ & $-46 \%$ & $28 \%$ & $25 \%$ & $-6 \%$ \\
\hline 355 & Productos de hule & $-26 \%$ & $-36 \%$ & $-11 \%$ & $57 \%$ & $65 \%$ & $8 \%$ \\
\hline 356 & Productos de ple1stico & $-26 \%$ & $-30 \%$ & $-3 \%$ & $64 \%$ & $49 \%$ & $-15 \%$ \\
\hline 361 & Objetos de barro, loza, porcel. & $-24 \%$ & $-29 \%$ & $-6 \%$ & $41 \%$ & $26 \%$ & $-15 \%$ \\
\hline 362 & Productos de vidrio & $-37 \%$ & $-42 \%$ & $-5 \%$ & $64 \%$ & $45 \%$ & $-19 \%$ \\
\hline 369 & Cemento y miner. no mete 11. & $-27 \%$ & $-31 \%$ & $-4 \%$ & $95 \%$ & $53 \%$ & $-42 \%$ \\
\hline 371 & Hierro y acero & $-14 \%$ & $-30 \%$ & $-16 \%$ & $59 \%$ & $30 \%$ & $-32 \%$ \\
\hline 381 & Maquinaria y prod. mete1licos & $-26 \%$ & $-34 \%$ & $-8 \%$ & $-12 \%$ & $26 \%$ & $37 \%$ \\
\hline 383 & Maquinaria ele9ctrica & $13 \%$ & $-29 \%$ & $-42 \%$ & $31 \%$ & $51 \%$ & $19 \%$ \\
\hline 384 & Equipo de transporte & $5 \%$ & $-29 \%$ & $-34 \%$ & $83 \%$ & $53 \%$ & $-30 \%$ \\
\hline 385 & Equipo profesional y cientedfico & $62 \%$ & $-35 \%$ & $-97 \%$ & $124 \%$ & $64 \%$ & $-59 \%$ \\
\hline 39 & Otros prod. manufacturados & $-41 \%$ & $-32 \%$ & $9 \%$ & $43 \%$ & $64 \%$ & $22 \%$ \\
\hline
\end{tabular}


1/ RULC es el costo unitario relativo de la mano de obra (E.U.A./ México) expresado en la misma moneda. Un número positivo implica que los costos unitarios están creciendo más rápido en E.U.A., lo que significa una posición más competitiva en cuanto a costo por mano de obra para México.

2/ RWL es el salario por trabajador relativo (E.U.A./ México) expresado en la misma moneda. Un número positivo implica que los salarios están creciendo más rápido en E.U.A., lo que significa una posición más competitiva en cuanto a costo por mano de obra para México.

3/ RO L es el producto por trabajador relativo (E.U.A./ México). Un número negativo implica que la productividad está creciendo más rápido en México, lo que significa una posición más competitiva en cuanto a costo por mano de obra para México.

El cuadro 3 muestra que existe una variación considerable de los cambios de RULC y sus componentes en las industrias manufactureras. En primer lugar, nótese que para el agregado manufacturero el componente del salario (RWL) explica casi el total del cambio de RULC, especialmente en el segundo subperiodo. Sin embargo, éste no es el caso para algunas industrias ya que hay algunos cambios importantes de ROL que tuvieron una contribución en la variación de RULC.

Una segunda observación es que los cambios de RWL en las industrias son más homogéneos que los cambios de ROL. La desviación estándar de los cambios de RWL es de 0.13 para ambos subperiodos, mientras que para ROL es 0.18 y 0.22 para el primero y segundo subperiodos respectivamente. Lo anterior significa que los cambios de los salarios relativos en las manufacturas son más homogéneos que la productividad laboral relativa.

Para entender mejor las diferencias en las manufacturas, la gráfica 2 ilustra los cambios de RULC y sus componentes entre 1980-1982 y 1992-1994. Con el fin de obtener una mejor apreciación gráfica, se tomó el inverso de ROL (1/ ROL), y por lo tanto ahora un número positivo de esa variable indica un mejoramiento del producto por trabajador de México en relación con E.U.A. Las industrias se muestran en orden ascendente con respecto a (1/ROL); es decir, de aquellas industrias para las cuales el producto por trabajador creció más rápido en E.U.A., hacia aquellas para las que la productividad laboral de México creció más rápido que la de E.U.A.

Si nos movemos de izquierda a derecha en la gráfica 2, la primera industria, maquinaria y productos metálicos (CIIU-381), muestra una disminución de RULC (apreciación). En términos de sus componentes, el cambio de RULC se explica por un cambio mayor del producto por trabajador en E.U.A. que en México (una reducción de 1/ROL) que el cambio de salarios por trabajador de E.U.A. en relación con México (incremento de RWL). En el otro extremo, para el Equipo profesional y científico (CIIU-39) tanto RWL como (1/ ROL) contribuyeron de manera sustancial y equitativa al cambio positivo de RULC (depreciación). Es claro que a medida que nos movemos de izquierda a derecha, el incremento de RULC se explica por el incremento de la productividad relativa de la mano de obra (1/ ROL).

Casi a la mitad de la distribución de las industrias se encuentra el cambio calculado de RULC y sus componentes para el total manufacturero, lo que nos ayuda a identificar qué industrias tuvieron mejores resultados (a la derecha) o peores (a la izquierda) que el promedio en cuanto al comportamiento de su productividad relativa.

En resumen, en esta sección se mostró que hubo una variación considerable del tipo de cambio real durante el periodo de análisis para las distintas industrias manufactureras. La variación de RULC para cada industria fue descompuesta en cambios de los salarios relativos expresados en dólares, y cambios de la productividad relativa del trabajo. Se mostró que tanto las variaciones de RULC como de sus componentes han sido muy distintas para las industrias. En las próximas secciones el análisis estará enfocado hacia la relación entre la variación de RULC y sus componentes y el 
comportamiento de las exportaciones de cada industria.

\section{Evaluación econométrica del comportamiento de las exportaciones}

En esta sección se presenta el análisis econométrico de las exportaciones de las industrias manufactureras. Los datos de exportaciones para todas las industrias a tres dígitos de agregación del CIIU sólo están disponibles de 1980 en adelante. Para algunas industrias se obtuvieron series anuales para la década de los 70s. Por lo anterior, se llevaron a cabo estimaciones para esas industrias durante el periodo 1970-1994, y posteriormente para la mayoría de las industrias para el lapso que va de 1983 a 1994, incluyendo en ambos casos el agregado manufacturero. Antes de proceder con las estimaciones, se consideran algunas cuestiones econométricas.

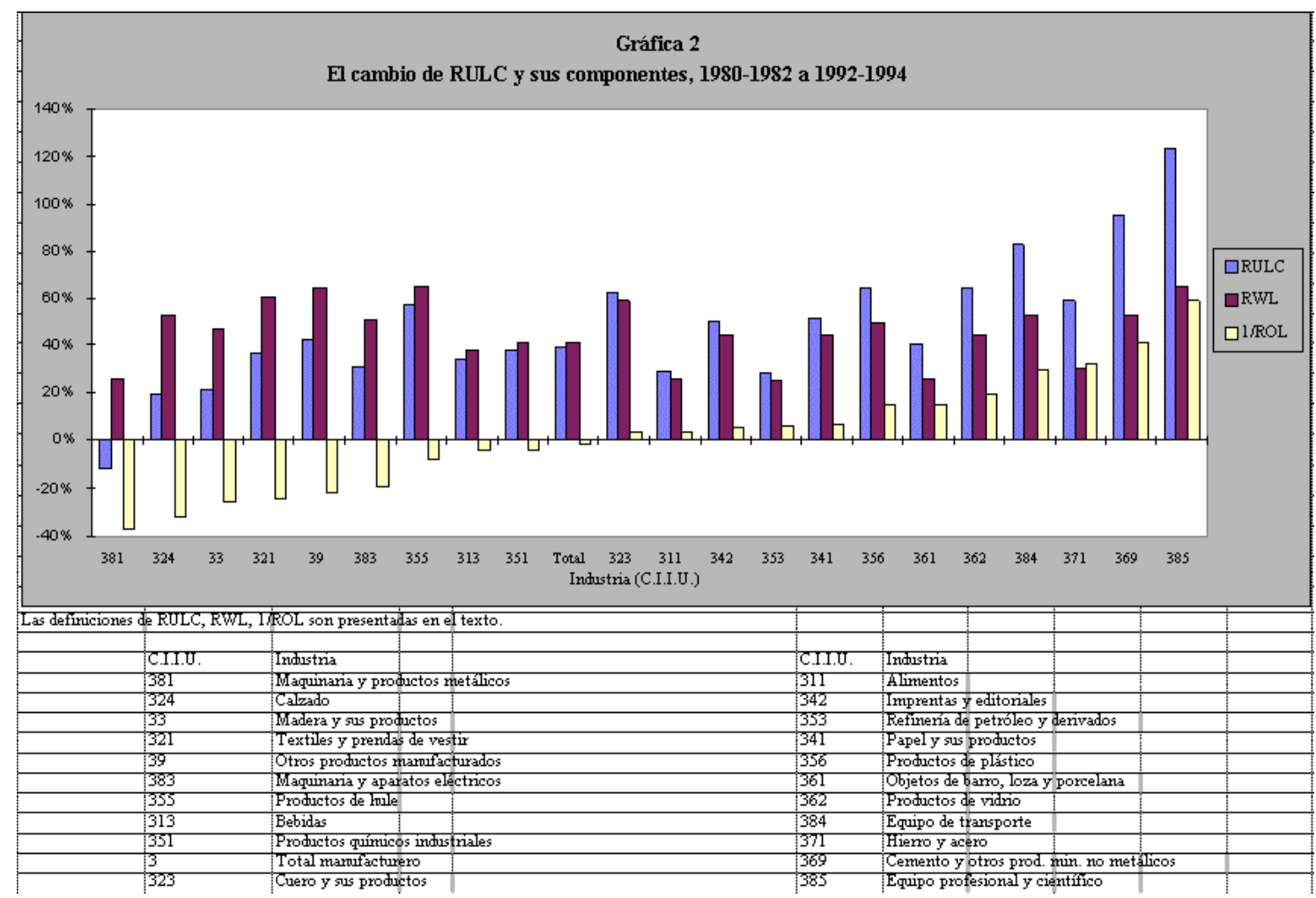

\subsection{Métodos econométricos}

El objetivo es identificar el grado de respuesta de exportadores de diferentes industrias a fluctuaciones del tipo de cambio real, manteniendo otros factores constantes. Estos otros factores están aproximados por la capacidad de oferta doméstica (IMP) y la demanda externa (MUS), como se explicaba anteriormente. La ecuación utilizada para esto es la ecuación (4) que ya se había derivado antes:

$$
X_{i t}=\gamma_{0 i}+\gamma_{1 i} R E R_{i t}+\gamma_{2 i} I M P_{i t}+\gamma_{3 i} M S_{i t}+u_{i t} \ldots \text { (4) }
$$

D onde RER es el tipo de cambio real (E.U.A./ México). RULC es el indicador del tipo de cambio real que será utilizado como se discutió en la sección anterior.

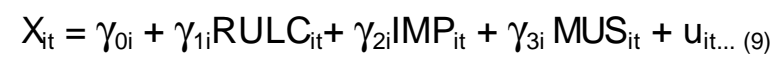

\subsubsection{Capacidad doméstica e importaciones extranjeras.}

La formulación de la ecuación (9) descansa en la argumentación teórica presentada anteriormente. 
Sin embargo, desde un punto de vista econométrico, los problemas que pueden surgir de la posible correlación entre IMP y MUS deben ser considerados. En la estimación de la ecuación (9) es importante que la posible correlación de IMP y MUS no afecte el valor y la significancia estadística del coeficiente asociado a RULC, que es el principal objetivo del ejercicio. Este problema ha sido enfrentado por otros analistas. (Casar (1991) propone esta idea en su estudio de la "ventaja comparativa revelada" de las manufacturas en México.) El valor de las elasticidades en la ecuación (9) no deberían estar influenciadas por la correlación entre IMP y MUS, como es bien conocido. Sin embargo, la varianza de los coeficientes estimados va a estar sobrestimada. Para verificar la solidez de los resultados, se calcularon los coeficientes de correlación entre IMP y MUS para cada industria, $\mathrm{y}$ en los casos en que el coeficiente era alto, IMP y MUS fueron excluidos alternativamente.

\subsubsection{Métodos de estimación.}

En principio, la ecuación (9) podría estimarse para cada industria utilizando el método de los mínimos cuadrados ordinarios (M.C.O.). Sin embargo, si la correlación de los residuales de las ecuaciones es alta, entonces se podrán obtener estimaciones más eficientes utilizando el método de ecuaciones aparentementenordacionadas (S.U.R., por sus siglas en inglés). Para saber si este problema es importante en el presente caso, se llevó a cabo la prueba Breusch-Pagan sobre la matriz de coeficientes de correlación de los residuales que se obtienen por M.C.O.

\subsubsection{Análisis de Cointegración.}

El análisis de cointegración y de raíces unitarias ha dominado el área de la econometría de series de tiempo en los últimos años. En esta literatura se muestra que no tiene sentido correr una regresión de una ecuación como la (9) cuando las variables no están integradas en el mismo orden, y además, si las variables no cointegran, la inferencia estadística (de las pruebas ty F) serán cuestionables.

En primer lugar se llevaron a cabo pruebas para establecer el orden de integración de las variables de la ecuación (9) para cada industria. Con pocas excepciones estas pruebas indicaron que las variables están integradas en orden uno, I(1). Se encontró que la variable dependiente en todos los casos era $\mathrm{I}(1)$, y en todos los casos había al menos una variable I(1) correspondiente en el lado derecho de la ecuación (9), de tal manera que se tiene una ecuación "balanceada" en el sentido econométrico.

Con respecto a las pruebas de cointegración, debe notarse que el reducido número de observaciones con que se cuenta hace dudar que dichas pruebas sean válidas en el presente caso. De acuerdo a Banerjee, etl. al. (1986), el primer paso del procedimiento propuesto por Engle y Granger, que consiste en realizar la prueba de cointegración usando la ecuación en niveles para obtener las elasticidades de largo plazo, no es apropiado cuando el tamaño de la muestra es pequeña. Por otro lado se puede hacer la prueba de cointegración usando el método propuesto por Johansen y Juselius (1990) en el que las elasticidades de largo plazo se obtienen en conjunto con la dinámica de corto plazo, lo cual reduce el sesgo de las elasticidades de largo plazo, a diferencia del primer paso del método de Engle y G ranger. Sin embargo, para estimar simultáneamente las elasticidades de corto y largo plazo se necesita un número suficiente de observaciones.

Finalmente se decidió estimar la ecuación (9) para cada sector por M.C.O . y basar nuestro análisis en estos resultados. Adicionalmente se estimó el modelo utilizando el método de Johansen y Juselius, y más adelante se comenta en que casos los resultados de ambos métodos difieren.

No puede negarse que otros factores diferentes al tipo de cambio real, a la capacidad doméstica y a las importaciones extranjeras, juegan un papel importante en la determinación de las exportaciones de México. La disponibilidad de infraestructura para la exportación, de información acerca de clientes potenciales, o de servicios financieros a costos competitivos internacionalmente deben ser factores importantes en la explicación del crecimiento de las exportaciones. Sin embargo, estos 
factores son difíciles de medir o no pueden tomarse en cuenta en análisis de regresión de series de tiempo anuales. Su ausencia puede ser importante para explicar los residuales de la ecuación. Sin embargo, es difícil saber si esos factores juegan un papel sistemático en la explicación de los residuales. La hipótesis es que esos factores no juegan un papel más importante en la explicación de las exportaciones que aquellos factores ya tomados en cuenta en la ecuación (9).

\subsubsection{Pruebas de Igualdad de coeficientes.}

Como ya ha sido explicado anteriormente es necesario establecer si distintos factores explican el crecimiento de las exportaciones de los sectores de la industria manufacturera. Mediante la estimación de la ecuación (9) para cada sector de manera independiente por M.C.O . se obtienen las elasticidades de las exportaciones con respecto a cada variable explicativa (RULC, IMP, MUS). Es importante evaluar si estas elasticidades son estadísticamente distintas para los sectores. Para ello se llevaron a cabo pruebas Chow de igualdad de coeficientes de las distintas ecuaciones. Estas pruebas se basan en la comparación entre modelos con y sin restricciones. El modelo sin restricciones corresponde a la ecuación (9) en donde las elasticidades pueden ser distintas para cada sector. La primera restricción que queremos probar es si todas las elasticidades son iguales para los sectores:

$$
X_{i t}=\gamma_{0}+\gamma_{1} R U L C_{i t}+\gamma_{2} M^{M} P_{i t}+\gamma_{3} M_{U S} S_{i t}+u_{i t} \ldots(9-r 1)
$$

donde los coeficientes $g$ son iguales para todos los sectores. Una segunda prueba es si las elasticidades con respecto a RULC son iguales:

$$
X_{i t}=\gamma_{0}+\gamma_{1} R U L C_{i t}+\gamma_{2 i} I M P_{i t}+\gamma_{3 i} M_{U S} S_{i t}+u_{i t} \ldots(9-r 2)
$$

donde ahora solamente g1 es igual para todos los sectores, mientras que g0, g2 y g3 varían para cada sector. La prueba consiste en obtener la suma de residuales al cuadrado de los modelos restringido (SSR1 y SSR2 respectivamente) y no restringido (SSR) y calcular el siguiente valor estadístico:

$$
\frac{\left(S S R-S S R_{j}\right) / k}{S S R_{j} /(T-2 k)}
$$

que se distribuye como $\mathrm{F}(\mathrm{k}, \mathrm{T}-\mathrm{k})$; donde $\mathrm{j}=1,2$; $\mathrm{k}$ es el número de parámetros restringidos y T es el producto del número de observaciones por el número de sectores. Estas pruebas se llevan a cabo en las siguientes secciones.

\subsection{El periodo 1970-1994.}

Las estimaciones iniciales mostraron dos problemas importantes. Primero, las series de tiempo de Xit para algunas industrias para las cuales estaban disponibles las series de 1970 a 1994 mostraron fuertes fluctuaciones, que volvieron vano el ejercicio de tratar de ajustar la ecuación (9) a los datos. Por lo tanto, el análisis solo se llevó a cabo para un grupo de industrias, aquéllas para las cuales se obtuvieron resultados razonables. Segundo, las estimaciones para algunos subperiodos mostraron cierta variabilidad de los coeficientes de la regresión, lo que resultó particularmente importante cuando el modelo fue ajustado dividiendo la muestra en 1982-1983. Como se explicó antes, hay por lo menos dos razones para esperar un cambio estructural a partir de 1983. Por un lado, hubo una depreciación importante del tipo de cambio real en ese año como consecuencia de la crisis de la deuda y de la escasez de flujos de capital. Por otro lado, se inició un proceso gradual de liberalización económica. Como lo documentan Salas y Alfaro (1992) y Peñaloza y V oljc (1989), a los exportadores se les garantizó el acceso libre de impuestos a la importación tanto de bienes de capital como intermedios. Este régimen existía desde mediados de los 70s, pero estaba condicionado al contenido doméstico de los productos exportados. Esas condiciones fueron gradualmente eliminadas. Por lo 
tanto, la ecuación (9) está estimada con los cambios en los parámetros ocurridos de 1983 en adelante en una sola ecuación usando variables dummy, como se muestra a continuación:

$$
\begin{gathered}
X_{i t}=\alpha_{0}+\alpha_{1 i} R U L C_{i t}+\alpha_{2 i} I M P_{i t}+\alpha_{3} M S_{i t}+\alpha_{4} D_{t}+\alpha_{5}\left(D_{t}^{*} R U L C_{i t}\right)+ \\
\alpha_{6}\left(D_{t}{ }^{*} I M P_{i t}\right)+\alpha_{7}\left(D_{t}^{*} M U S_{i t}\right)+u_{i t} \ldots(10)
\end{gathered}
$$

donde D t es una variable dummy que toma valor 0 de 1970 hasta 1982, y 1 en los años restantes. (Una prueba estadística formal para el cambio estructural es la prueba de Chow de igualdad de los coeficientes de la regresión en dos periodos de la muestra; 1970-1982 y 1983-1994 en este caso. Los resultados de esta prueba se reportan más adelante.)

Inicialmente los parámetros de cambio para las tres variables explicativas y la constante fueron incluidos. Basados en la prueba t, se eliminaron aquellos cambios de parámetros que no fueron significativos. Observaciones rezagadas también fueron incluidas inicialmente para cada variable, añadiendo los parámetros de cambio. Como se utilizan datos anuales, se decidió usar sólo un periodo de rezago. Es posible que cambios en $\mathrm{X}$ en respuesta a cambios en las variables explicativas tomen más de un año, pero el tamaño de la muestra limitó la inclusión de dos o más años de rezago. Los resultados se presentan en el cuadro 4.

Los resultados para el total del sector manufacturero (CIIU-3) son analizados en primer lugar. El primer punto importante es que los parámetros de cambio ( 4.. 7) son estadísticamente significativos, lo cual indica que hubo un cambio estructural en la ecuación. Para el primer subperiodo, 1 y 3 son significativos al 5\%, pero el primero con un signo (negativo) no esperado. El coeficiente asociado con IMP no es significativo. Para los 80s los tres coeficientes cambiaron. La elasticidad con respecto a RULC se volvió positiva (1+5), aunque es baja. IMP y MUS parecen intercambiar su papel: la elasticidad de la primera se volvió positiva $(2+6)$ y significativa, mientras que la última $(3+7)$ decreció. De esta manera, el volumen agregado de exportaciones fue determinado principalmente por la variable de demanda extranjera en los 70s, mientras que el ajuste en el nivel del tipo de cambio real en 1983, y la expansión de la capacidad doméstica en la década de 1980, explican la variación de las exportaciones en el segundo subperiodo. 
Cuadro 4

Resultados de la regresión para 1970-1994(Ecuación 10)

\begin{tabular}{|c|c|c|c|c|c|c|c|c|}
\hline & \multicolumn{8}{|c|}{ COEFICIENTES $1 /$} \\
\hline $\begin{array}{c}\text { INDUSTRIA } \\
\text { C.IIU. }\end{array}$ & $q_{0}$ & $\alpha_{1}$ & $a_{2}$ & $\alpha_{3}$ & $\alpha_{4}$ & $\alpha_{s}$ & $\alpha_{6}$ & $\alpha_{p}$ \\
\hline 3 & 2.9 & $.0 .72^{* *}$ & -0.60 & $165 *$ & $-12.2 *$ & $0.90 * *$ & $2.48 *$ & -0.72 \\
\hline Total marufistarero & (1.5) & $(2.0)$ & $(1.63)$ & $(4.85)$ & (3.1) & (2.1) & $(3.0)$ & (1.0) \\
\hline 311 & $-11.2^{*}$ & $0.99 *$ & $1.27^{*}$ & $1.2^{*}$ & $10.5^{*}$ & -0.37 & -0.88 & -1.1 \\
\hline Alminatos & $(4.5)$ & (3.01) & $(4.8)$ & (3.2) & (2.2) & $(0.97)$ & (0.8) & (1.38) \\
\hline 351 & $9.0^{*}$ & $-10^{*}$ & $-1.1^{*}$ & $1.15^{*}$ & $-176^{*}$ & $1.24^{*}$ & $3.1^{*}$ & -0.5 \\
\hline Produtos qúmicos & (3.5) & (2.8) & (3.5) & $(5.49)$ & (4.4) & (2.9) & (4.1) & (1.4) \\
\hline 362 & 0.81 & $.0 .29 * * \mathrm{~L}(1)$ & $0.86^{*}$ & 0.28 & $-6.3 *$ & -0.03 & 0.34 & $1.1^{*}$ \\
\hline Produtos de vitio & (0.8) & $(1.80)$ & (3.7) & (1.1) & (2.9) & $(0.12)$ & $(0.79)$ & (3.01) \\
\hline 371 & $-9.3^{*}$ & $2.74^{*}$ & -0.11 & 0.45 & -2.5 & $-1.68 * *$ & $3.84^{*}$ & -1.39 \\
\hline Hiero y acero & (2.2) & (3.98) & $(0.28)$ & $(0.69)$ & (0.5) & (2.1) & (4.34) & (1.58) \\
\hline \multirow{4}{*}{ Equipo de transporte } & \multirow{4}{*}{$\begin{array}{l}-4.76 * \\
(4.4)\end{array}$} & $0.58 *$ & $0.43^{*}$ & \multirow{3}{*}{$1.08 *$} & & \multirow[b]{2}{*}{$-0.33^{* *}$} & \multirow{3}{*}{$0.55^{*}$} & \\
\hline & & & & & & & & \\
\hline & & $\mathrm{L}(1)$ & $\mathrm{L}(1)$ & & & 187 & & \\
\hline & & $(2.32)$ & (2.13) & & & & & \\
\hline
\end{tabular}




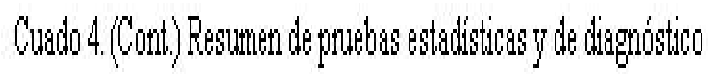

\begin{tabular}{|c|c|c|c|c|c|c|c|c|}
\hline Industitia & \multicolumn{4}{|c|}{ BESIMEN ESTADITTOO } & \multicolumn{4}{|c|}{ PRLEBS DE DIAGOOTTCOSI } \\
\hline & $\mathbb{R}^{2}$ & Prublat & SER & D.W. & Prublachory & Funct Foum & Mommididad & Hetertoced \\
\hline $\begin{array}{c}3 \\
\text { Intal mindititron }\end{array}$ & 0982 & $(7,17)=192,44$ & 0.097 & 206 & $4.15^{*}$ & 242 & 24 & 0.1 \\
\hline 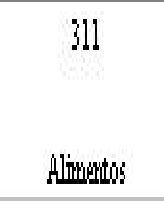 & 0.74 & $(7,17)=10.80$ & 0.121 & 20 & $756 *$ & 05 & 16 & 566 \\
\hline 311 & 0972 & $(7,17)=1209$ & $0.107 ?$ & 184 & $75 \%$ & 1.3 & 0.4 & 10 \\
\hline 36 & 0.982 & $(7,16)=168.2$ & 0.121 & 1.64 & $370^{*}$ & 12 & 0.1 & 22 \\
\hline $\begin{array}{c}311 \\
\text { Himo yien }\end{array}$ & 092 & $(0,17)=48.4$ & 0288 & 184 & $86^{*}$ & 0.7 & 13 & 24 \\
\hline 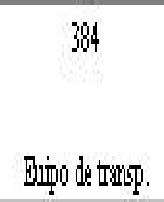 & 0981 & $(5,18)=25.4$ & 0.169 & 1.42 & $15 !^{*}$ & 0.74 & 1.1 & 6.67 \\
\hline
\end{tabular}


Notas:

1/ El número en paréntesis debajo de los coeficientes corresponde a la prueba t, con los niveles de significancia denotados como: $*=5 \%, * *=10 \%$. L(1) significa que la variable en la ecuación está rezagada un año.

2/ Los grados de libertad para la prueba de significancia $F$ son ( $k-1, n-k)$, donde $k$ es el número de parámetros estimados $(3,50$ 7) y $n=23$. Valores críticos a $1 \%$ y $5 \%$ son respectivamente: $(2,20)=5.85$ y $3.49 ;(4,18)=4.58$ y $2.93,(6,16)=4.03$ y 2.66 .

3/ Pruebas de diagnóstico:

Prueba Chow: prueba la igualdad de los coeficientes de la regresión en los periodos 1970-1982 y 1983-1994 de la muestra. Versión F. Un * significa el rechazo de la hipótesis nula de igualdad de coeficientes en ambos periodos de la muestra.

Fun. form: Ramsey's RESET test. F version.

Heterosced. Prueba para heteroscedasticidad basada en la regresión de los residuales al cuadrado en los valores ajustados al cuadrado. Versión F.

Normalidad: basada en pruebas de asimetría y kurtosis de los residuales. Versión 2.

Conviene preguntarse si la inclusión de IMP y de MUS en la ecuación puede influenciar los resultados. Hay que recordar que la regresión incluye a IMP y a MUS porque ésta es la ecuación para cantidades exportadas. El coeficiente de correlación entre las variables es 0.915 para el periodo 19701994 y 0.920 y 0.833 para los subperiodos respectivamente. Más específicamente, ¿fue insignificante la expansión del producto manufacturero en la explicación de las exportaciones en el primer subperiodo?, ¿Tuvo la expansión del volumen de importaciones de E.U.A. algún efecto en el crecimiento de las exportaciones mexicanas durante la década de los 80s? Con el fin de explorar esta cuestión, IMP y MUS fueron alternativamente excluídas de la ecuación.

Si MUS es excluída de la ecuación (los resultados no se presentan) la elasticidad con respecto a IMP se vuelve positiva y significativa para ambos subperiodos, mientras que el coeficiente RULC conserva su valor (negativo en los 70s y positivo en los 80s) y su significancia. Sin embargo, la exclusión de MUS provoca que rechacemos la hipótesis de que la forma funcional de los residuales es correcta, lo que sugiere que ninguna de las variables explicativas (RULC y IMP) toma en cuenta correctamente la evolución de las exportaciones, especialmente en la década de 1970.

Por su parte, cuando IMP es excluída se obtienen los siguientes resultados. RULC no es significativa en ninguno de los periodos, MUS es muy significativa y el parámetro de cambio asociado con esta variable no es significativo. En otras palabras, la correlación entre IMP y MUS tiene influencia en el valor y significancia de las elasticidades asociadas a esas variables.

Parece ser entonces que IMP y MUS son ambos factores explicativos importantes del crecimiento de las exportaciones, como se esperaba. ¿Cual es la lógica de estos resultados? Antes de comentar las implicaciones de los resultados agregados, la misma ecuación de regresión es estimada para industrias individuales. Precisamente el principal objetivo de este trabajo es establecer si los patrones encontrados para todas las manufacturas se basan en el comportamiento de los diferentes sectores.

CIIU-311. Productos alimenticios manufacturados.

Los resultados de la regresión en este caso muestran coeficientes significativos para las tres variables con los signos esperados, mientras que sólo el cambio del coeficiente asociado a la constante (4) es significativo. La hipótesis de homoscedasticidad de los residuales es rechazada al 5\%. Esto es así porque el ajuste del modelo es mejor en el primer subperiodo. Nótese que el coeficiente R2 es el 
más bajo en la muestra de las industrias. Al hacer los cálculos para obtener las elasticidades del subperiodo 1983-1994, se obtuvo que sólo la elasticidad RULC era significativa.

CIIU-351. Industria química.

Los resultados de esta industria son similares a los del agregado manufacturero. X está explicada por MUS durante los 70s, y por IMP durante los 80s. Sin embargo, si MUS es excluída, las elasticidades con respecto a RULC y a IMP se vuelven no significativas, el parámetro de cambio asociado con RULC no es significativo y el relacionado con IMP no cambia. Por lo tanto, la evolución de X durante los 70s está más relacionada a MUS, mientras que para los 80s IMP y MUS determinan las exportaciones.

CIIU-362 Industria del Vidrio.

La expansión de la producción de la industria parece ser el principal determinante en el comportamiento de las exportaciones. Los cambios en los parámetros son estadísticamente no significativos para RULC y para IMP, pero no para MUS. De acuerdo con los resultados de la regresión, IMP es el determinante a lo largo del periodo, y MUS se vuelve significativo en el segundo subperiodo.

CIIU-371 Industria del hierro y el acero.

Los resultados de la regresión muestran una influencia importante de RULC para todo el periodo. La elasticidad de X con respecto a IMP tuvo un incremento importante en la década de 1980. MUS no es significativa en ninguno de los dos subperiodos, y no se debe a la inclusión de IMP. La correlación entre MUS y IMP es la más baja de la muestra.

CIIU-384 Equipo de transporte.

Las exportaciones de la industria están determinadas por tres variables independientes durante la década de 1970. Los coeficientes de cambio para RULC e IMP son significativos, aunque bajos. Por lo tanto las exportaciones de esta industria son sensibles a variaciones de RULC y también a la capacidad doméstica y demanda extranjera.

Antes de profundizar en el análisis de los resultados, conviene establecer si las elasticidades y sus cambios a partir de 1983 son estadísticamente diferentes para los sectores. Para ello se presentan los resultados de la prueba de Chow de igualdad de los coeficientes introducido anteriormente (véase sección 4.1.4). Al restringir todos los coeficientes de la ecuación (10) a ser iguales para los sectores, se obtiene un valor del estadístico igual a 204.7 que es muy superior al valor crítico (al 5\%, con 8 y 109 grados de libertad) que es de 3.8, por lo que la hipótesis nula de igualdad de las elasticidades se rechaza. La segunda prueba es sobre la igualdad de las elasticidades asociadas a RULC. Esta prueba también se rechaza ya que el valor estimado del estadístico es de 156.7. De esta manera, tenemos evidencia de que los distintos sectores no parecen responder de la misma manera a los cambios de las variables explicativas.

Las principales observaciones que surgen de las regresiones para el periodo 1970-1994 son las siguientes. Primero, en relación con el grado de respuesta de las exportaciones a variaciones de RULC, para el agregado manufacturero (CIIU 3) y los químicos y el vidrio (CIIU 351 y 362), los resultados muestran un signo negativo no esperado y apenas estadísticamente significativo para los años 70s. De cualquier modo, estas elasticidades se incrementaron a partir de 1983. Para las otras tres industrias consideradas, alimentos, hierro y acero y equipo de transporte (CIIU 311,371 y 384), la elasticidad de RULC es positiva para los 70s, como se esperaba, y luego decreció a partir de 1983. En otras palabras, durante los 70s las exportaciones de algunas industrias (CIIU 311,371 y 384) se incrementaron (disminuyeron) con una depreciación real (apreciación) del tipo de cambio, como se esperaría de acuerdo con el modelo de este capítulo. Pero para otras industrias (CIIU 351 y 362, y 
para el total manufacturero) esta relación se da en dirección contraria. Una posible explicación de este resultado es que una devaluación puede tener efectos contractivos en algunas industrias, porque su proceso productivo es intensivo en insumos importados, que se encarecen al momento de una depreciación. O tras industrias pueden resolver ese problema si las transacciones se llevan a cabo al interior de las empresas, ya que así pueden obtener bienes importados sin importar los movimientos del tipo de cambio, como la industria de equipo de transporte (CIIU-384), o si las empresas tienen acceso a moneda extranjera que no está fácilmente disponible, como la industria de hierro y acero (CIIU-371, compañías del Estado), o simplemente si no utilizan insumos importados muy intensamente (CIIU 311).

La segunda conclusión es que hubo un incremento de las elasticidades con respecto a IMP, MUS o ambas empezando en 1983, con excepción de la industria alimenticia. Esto significa que después de ese año las exportaciones de las empresas manufactureras en México respondieron más a la demanda extranjera y a la expansión de la capacidad doméstica, lo que se podría explicar por la depreciación real del tipo de cambio que tuvo lugar en 1983, que hizo más rentables las exportaciones, y por el cambio en la política de comercio, especialmente la decisión de permitir a las empresas importar insumos para el proceso de exportación.

Antes de concluir esta sección, debemos verificar que los resultados sean sólidos. Primero se llevó a cabo una prueba a la matriz de correlación de los coeficientes de los residuales, y en segundo lugar, se corrieron otra vez las regresiones para algunas industrias utilizando los precios relativos como indicadores del tipo de cambio real, y a la tendencia del producto como aproximación de la capacidad. (También debemos comentar acerca de los resultados que se obtienen al estimar la ecuación (10) por el método de Johansen (ver sección 4.1.3). En todos los casos se encontró que efectivamente las variables cointegran y los vectores de cointegración son muy similares a los obtenidos por M.C.O., con dos excepciones: en el caso de la industria del vidrio, la elasticidad con respecto a RULC es negativa y no cambia a partir de 1983, y en el caso de la industria del hierro y el acero los resultados son muy parecidos si MUS es excluída, lo cual no afecta los resultados para esta industria.)

La matriz de correlación de los residuales de las regresiones se presenta a continuación. (El agregado manufacturero (CIIU-3) obviamente se excluye, ya que puede surgir correlación porque una de sus partes (cualquier industria CIIU) puede influír los resultados del agregado.)

Cuadro 5

Matriz de correlación de los residuales obtenidos por MCO; 1970-1994

\begin{tabular}{|l|c|c|c|c|}
\hline & CIIU-311 & CIIU-351 & CIIU-362 & CIIU-371 \\
\hline CIIU-351 & 0.074 & & & \\
\hline CIIU-362 & 0.358 & 0.454 & & \\
\hline CIIU-371 & 0.155 & -0.026 & -0.193 & \\
\hline CIIU-384 & 0.036 & 0.084 & 0.506 & -0.048 \\
\hline
\end{tabular}

Algunos de los coeficientes de correlación son altos. Una prueba estadística formal para saber si la matriz es diagonal es la prueba de Breusch y Pagan (1980). La prueba estadística empleada es:

$$
\lambda=T \sum_{i=2}^{M} \sum_{j=1}^{i-1} r_{i j}^{2}
$$

para una muestra de $\mathrm{T}$ observaciones y $\mathrm{M}$ ecuaciones, donde rij2 es el cuadrado del coeficiente de correlación de cada par de residuales. Esta prueba sigue una distribución 2 con $\mathrm{M}(\mathrm{M}-1) / 2$ grados de libertad, bajo la hipótesis nula de una matriz de covarianza diagonal. En el caso de las ecuaciones 
presentadas arriba, el valor de este estadístico es 16.7, que es ligeramente menor que el valor crítico (5\%) de 18.3. Por lo tanto, la hipótesis nula de una matriz de covarianza diagonal no es rechazada, lo cual implica que no se obtendría una gran ventaja en términos de eficiencia corriendo las ecuaciones mediante SUR, es decir, tomando en cuenta la correlación cruzada de los residuales.

Los resultados de la regresión utilizando precios relativos (RP) en lugar de RULC como indicador del tipo de cambio real para cada industria son presentados en el cuadro A.1 (ver apéndice). (Las regresiones utilizando RP para CIIU 311, 371 y 384 fueron muy similares a las que se obtuvieron utilizando RULC y no son presentadas.) Los resultados muestran que los coeficientes no varían mucho, pero algunos de ellos son no significativos, hasta al 10\%. Este es el caso de las elasticidades RP y sus parámetros de cambios (1 y 4), que contradice el resultado obtenido para la elasticidad RULC del total manufacturero, y el de las industrias química y del vidrio (CIIU 3, 351 y 362). Por otro lado, las elasticidades con respecto a IMP y MUS son muy similares. Con excepción de este resultado, las principales conclusiones obtenidas antes no varían al utilizar RP en lugar de RULC.

Finalmente, los resultados que se obtienen con el uso de la tendencia del producto como indicador de la capacidad en lugar del producto observado no difieren mucho. Estos resultados se presentan en el cuadro A.3. Es importante notar que esta conclusión sólo se obtiene cuando usamos trayectorias lineales, cuadráticas y cúbicas para obtener la tendencia del producto.

\subsection{El periodo 1983-1994.}

Como se explicó anteriormente, los datos para la década de 1980 son más confiables y más desagregados. Además de aquellas industrias consideradas anteriormente, en esta sección se añaden otras al análisis. Por las razones expuestas en la sección anterior, la estimación se lleva a cabo para el periodo 1983-1994. En caso de que las variables de ingreso IMP y MUS estuvieran muy correlacionadas, la ecuación se estima otra vez excluyendo a MUS, para verificar si cambian el coeficiente y la significancia estadística de la variable RULC. Las pruebas de diagnóstico de correlación seriada, forma funcional, heteroscedasticidad y normalidad de los residuales no se presentan, ya que se encontró que éstos no presentan dichos problemas. Los resultados se presentan a continuación. 
Cuadro 6

Resultados de la regresión, 1983-1994 (Ecuación 6)

\begin{tabular}{|c|c|c|c|c|c|c|c|c|}
\hline Industria & \multicolumn{4}{|c|}{ COEFICIENTES $1 /$} & \multicolumn{4}{|c|}{ RESUMEN ESTADÍSTICO 2/ } \\
\hline C.I.I.U. & Constant & RULC & IMP & MUS & $\mathrm{R}^{2}$ & Prueba F & S.E.R. & D.W. \\
\hline $\begin{array}{c}3 \\
\text { Total }\end{array}$ & $\begin{array}{l}-9.2^{*} \\
(2.5)\end{array}$ & $\begin{array}{c}0.18 \\
(0.64)\end{array}$ & $\begin{array}{l}1.9^{*} \\
(2.3)\end{array}$ & $\begin{array}{l}0.93^{*} \\
(3.0)\end{array}$ & 0.93 & & 0.107 & 1.45 \\
\hline $\begin{array}{l}\text { Manufactu- } \\
\text { rero }\end{array}$ & $\begin{array}{c}-17.5^{\star} \\
(5.2)\end{array}$ & $\begin{array}{l}0.73^{*} \\
(2.45)\end{array}$ & $\begin{array}{l}4.09^{*} \\
(8.48)\end{array}$ & & 0.87 & & 0.147 & 1.28 \\
\hline $\begin{array}{c}311 \\
\text { Alimentos }\end{array}$ & $\begin{array}{l}-1.1 \\
(0.3)\end{array}$ & $\begin{array}{l}0.62^{*} \\
(2.4)\end{array}$ & $\begin{array}{c}0.4 \\
(0.4)\end{array}$ & $\begin{array}{c}0.13 \\
(0.19)\end{array}$ & 0.43 & $(3,8)=3.74$ & 0.107 & 2.2 \\
\hline 313 & $\begin{array}{l}-29.7^{\star} \\
(6.8)\end{array}$ & $\begin{array}{l}1.6^{*} \\
(4.9)\end{array}$ & $\begin{array}{l}3.0^{*} \\
(5.5)\end{array}$ & $\begin{array}{l}2.5^{\star} \\
(2.8)\end{array}$ & 0.89 & $(3,8)=33.1$ & 0.15 & 2.5 \\
\hline Bebidas & $\begin{array}{l}-22.9^{*} \\
(4.8)\end{array}$ & $\begin{array}{l}1.8^{*} \\
(4.1)\end{array}$ & $\begin{array}{l}3.95^{*} \\
(6.87)\end{array}$ & & 0.82 & $(2,9)=6.9$ & 0.204 & 1.49 \\
\hline $\begin{array}{c}321 \\
\text { Textiles }\end{array}$ & $\begin{array}{c}14.8^{\star *} \\
(2.1)\end{array}$ & $\begin{array}{l}0.15 \\
(0.5)\end{array}$ & $\begin{array}{l}-3.4^{*} \\
(2.3)\end{array}$ & $\begin{array}{c}0.97^{\star}(\mathrm{L} 1) \\
(5.6)\end{array}$ & 0.85 & $(3,8)=22.1$ & 0.173 & 1.97 \\
\hline $\begin{array}{l}323 \\
\text { Cuero }\end{array}$ & $\begin{array}{l}-20.1^{*} \\
(3.4)\end{array}$ & $\begin{array}{l}-0.25 \\
(0.53)\end{array}$ & $\begin{array}{l}0.83 \\
(0.9)\end{array}$ & $\begin{array}{c}4.5^{\star}(\mathrm{L} 2) \\
(9.8)\end{array}$ & 0.92 & $(3,8)=44.0$ & 0.21 & 1.81 \\
\hline $\begin{array}{c}324 \\
\text { Calzado }\end{array}$ & $\begin{array}{c}7.7 \\
(1.4)\end{array}$ & $\begin{array}{l}0.07 \\
(0.2)\end{array}$ & $\begin{array}{l}-2.2^{*} \\
(2.3)\end{array}$ & $\begin{array}{c}1.2^{\star} \mathrm{L}(2) \\
(2.35)\end{array}$ & 0.87 & $(3,8)=26.4$ & 0.270 & 1.43 \\
\hline $\begin{array}{c}33 \\
\text { Madera }\end{array}$ & $\begin{array}{c}18.76^{\star *} \\
(2.07)\end{array}$ & $\begin{array}{c}0.06 \\
(0.14)\end{array}$ & $\begin{array}{c}-4.27^{\star *} \\
(1.91)\end{array}$ & $\begin{array}{l}1.12^{*} \\
(3.5)\end{array}$ & 0.57 & $(3,8)=5.86$ & 0.202 & 1.45 \\
\hline 341 & $\begin{array}{l}-7.0 \\
(0.8)\end{array}$ & $\begin{array}{r}1.38 \\
(1.25)\end{array}$ & $\begin{array}{r}-1.79 \\
(0.8)\end{array}$ & $\begin{array}{c}3.19^{\star}(\mathrm{L} 1) \\
(2.65)\end{array}$ & 0.70 & $(3,8)=9.7$ & 0.270 & 1.65 \\
\hline Papel & $\begin{array}{l}-22.7^{*} \\
(2.8)\end{array}$ & $\begin{array}{l}1.95^{\star} \\
(2.64)\end{array}$ & $\begin{array}{l}4.09^{*} \\
(3.22)\end{array}$ & & 0.50 & $(2,9)=6.6$ & 0.352 & 1.72 \\
\hline 351 & $\begin{array}{l}-8.6^{*} \\
(3.1)\end{array}$ & $\begin{array}{l}0.24 \\
(1.1)\end{array}$ & $\begin{array}{l}1.95^{\star} \\
(3.1)\end{array}$ & $\begin{array}{l}0.62^{*} \\
(2.3)\end{array}$ & 0.94 & $(3,8)=61.9$ & 0.099 & 1.62 \\
\hline Químicos & $\begin{array}{l}-11.5^{\star} \\
(3.8)\end{array}$ & $\begin{array}{l}0.24 \\
(0.9)\end{array}$ & $\begin{array}{l}3.2^{*} \\
(8.4)\end{array}$ & & 0.92 & $(2,9)=$ & 0.121 & 1.72 \\
\hline $\begin{array}{l}355 \\
\text { Hule }\end{array}$ & $\begin{array}{l}12.0 \\
(1.5)\end{array}$ & $\begin{array}{c}1.18^{\star \star}(\mathrm{L} 1) \\
(2.1)\end{array}$ & $\begin{array}{c}-4.0 \\
(1.70)\end{array}$ & $\begin{array}{l}1.41^{*} \\
(2.7)\end{array}$ & 0.61 & $(3,8)=6.67$ & 0.40 & 1.82 \\
\hline 356 & $\begin{array}{r}-12.2 \\
(0.9)\end{array}$ & $\begin{array}{c}0.5 \\
(0.5)\end{array}$ & $\begin{array}{c}2.7 \\
(0.7)\end{array}$ & $\begin{array}{c}0.43 \\
(0.25)\end{array}$ & 0.79 & & 0.30 & 2.2 \\
\hline Plásticos & $-13.3^{*}$ & $0.75^{\star}(\mathrm{L} 1)$ & $3.2^{*}$ & & 0.84 & $(2,9)=29.1$ & 0.295 & 1.87 \\
\hline
\end{tabular}




\begin{tabular}{|c|c|c|c|c|c|c|c|c|}
\hline & (5.2) & (2.37) & $(5.8)$ & & & & & \\
\hline 361 & $\begin{array}{l}-25.9^{*} \\
(2.8)\end{array}$ & $\begin{array}{l}0.86 \\
(1.1)\end{array}$ & $\begin{array}{l}5.2^{* \star} \\
(2.1)\end{array}$ & $\begin{array}{l}0.37 \\
(0.3)\end{array}$ & 0.87 & & 0.21 & 1.6 \\
\hline $\begin{array}{l}\text { Objetos de } \\
\text { barro, loza } \\
\text { porcelana }\end{array}$ & $\begin{array}{l}-28.1^{*} \\
(6.2)\end{array}$ & $\begin{array}{l}1.03^{*} \\
(2.45)\end{array}$ & $\begin{array}{l}5.9^{*} \\
(9.1)\end{array}$ & & 0.89 & $(2,9)=43.8$ & 0.197 & 1.59 \\
\hline $\begin{array}{c}362 \\
\text { Vidrio }\end{array}$ & $\begin{array}{l}-4.8^{*} \\
(3.8)\end{array}$ & $\begin{array}{l}-0.2 \\
(1.1)\end{array}$ & $\begin{array}{l}1.2^{*} \\
(4.3)\end{array}$ & $\begin{array}{l}1.2^{*} \\
(5.7)\end{array}$ & 0.96 & $(2,9)=85.8$ & 0.090 & 2.4 \\
\hline 369 & $\begin{array}{l}0.5 \\
(0.3)\end{array}$ & $\begin{array}{l}0.1 \\
(0.3)\end{array}$ & $\begin{array}{l}-0.01 \\
(0.0)\end{array}$ & $\begin{array}{l}0.91^{*} \\
(2.34)\end{array}$ & 0.80 & $(3,8)=16.1$ & 0.12 & 1.92 \\
\hline Cemento & $\begin{array}{l}-2.09 \\
(1.25)\end{array}$ & $\begin{array}{l}0.53^{*} \\
(3.27)\end{array}$ & $\begin{array}{l}1.02^{*} \\
(2.68)\end{array}$ & & 0.71 & $(2,9)=14.3$ & 0.153 & 1.79 \\
\hline 371 & $\begin{array}{r}-11.8^{*} \\
(4.3)\end{array}$ & $\begin{array}{l}1.1^{*} \\
(3.3)\end{array}$ & $\begin{array}{l}3.7^{*} \\
(6.3)\end{array}$ & $\begin{array}{l}-0.9^{* *} \\
(2.1)\end{array}$ & 0.83 & $(3,8)=19.0$ & 0.196 & 1.71 \\
\hline $\begin{array}{c}\text { Hierro y } \\
\text { acero }\end{array}$ & $\begin{array}{c}-12.9^{*} \\
(4.1)\end{array}$ & $\begin{array}{l}1.06^{*} \\
(2.8)\end{array}$ & $\begin{array}{l}3.02^{*} \\
(5.31)\end{array}$ & & 0.77 & $(2,9)=19.3$ & 0.230 & 1.04 \\
\hline $\begin{array}{c}381 \\
\text { Maquin. }\end{array}$ & $\begin{array}{l}-19.5^{*} \\
(2.9)\end{array}$ & $\begin{array}{l}1.0^{* *} \\
(1.9)\end{array}$ & $\begin{array}{l}3.3^{*} \\
(3.0)\end{array}$ & $\begin{array}{l}1.1^{*} \\
(4.4)\end{array}$ & 0.93 & $(3,8)=46.5$ & 0.19 & 1.80 \\
\hline $\begin{array}{l}\text { y prod. } \\
\text { metálicos }\end{array}$ & $\begin{array}{l}-31.3^{*} \\
(2.9)\end{array}$ & $\begin{array}{c}1.83^{\text {** }} \\
(1.8)\end{array}$ & $\begin{array}{l}6.41^{*} \\
(4.5)\end{array}$ & & 0.77 & $(2,9)=19.6$ & 0.337 & 1.59 \\
\hline 383 & $\begin{array}{c}-10.1^{\star *} \\
(2.0)\end{array}$ & $\begin{array}{l}0.0 \\
(0.0)\end{array}$ & $\begin{array}{l}1.6 \\
(1.6)\end{array}$ & $\begin{array}{l}1.6^{*} \\
(2.4)\end{array}$ & 0.90 & $(3,8)=34.4$ & 0.26 & 1.76 \\
\hline $\begin{array}{l}\text { Maquinaria } \\
\text { eléctrica }\end{array}$ & $\begin{array}{c}-15.6^{*} \\
(2.5)\end{array}$ & $\begin{array}{c}0.33 \\
(0.52)\end{array}$ & $\begin{array}{l}4.29^{*} \\
(6.63)\end{array}$ & & 0.85 & $(2,9)=31.9$ & 0.316 & 1.71 \\
\hline 384 & $\begin{array}{l}-5.5^{*} \\
(3.9)\end{array}$ & $\begin{array}{l}0.42^{*} \\
(2.5)\end{array}$ & $\begin{array}{l}0.91^{*} \\
(7.5)\end{array}$ & $\begin{array}{l}1.05^{\star} \\
(3.2)\end{array}$ & 0.94 & $(3,8)=62.5$ & 0.121 & 1.75 \\
\hline $\begin{array}{l}\text { Equipo de } \\
\text { transporte }\end{array}$ & $\begin{array}{l}-1.87 \\
(1.6)\end{array}$ & $\begin{array}{l}0.58^{*} \\
(2.48)\end{array}$ & $\begin{array}{l}1.1^{*} \\
(7.2)\end{array}$ & & 0.88 & $(2,9)=44.3$ & 0.171 & 1.18 \\
\hline $\begin{array}{c}385 \\
\text { Equipo }\end{array}$ & $\begin{array}{l}-8.9^{\star *} \\
(2.1)\end{array}$ & $\begin{array}{l}0.1 \\
(0.3)\end{array}$ & $\begin{array}{c}1.9 \\
(1.4)\end{array}$ & $\begin{array}{l}1.0^{*} \\
(2.4)\end{array}$ & 0.87 & $(3,8)=26.2$ & 0.27 & 1.5 \\
\hline $\begin{array}{l}\text { profes. y } \\
\text { científico }\end{array}$ & $\begin{array}{c}-18.5^{\star} \\
(5.4)\end{array}$ & $\begin{array}{l}0.55^{*} \\
(2.38)\end{array}$ & $\begin{array}{c}4.59 \mathrm{~L}\left({ }^{*} 1\right) \\
(6.44)\end{array}$ & & 0.83 & $(2,9=27.4$ & 0.315 & 1.04 \\
\hline
\end{tabular}


1/ El número que está debajo en paréntesis son los coeficientes de las t's, con niveles de significancia denotados como: ${ }^{*}=5 \%, * *=10 \%$. L(1) significa que la variable en la ecuación está rezagada un año.

2/ R2 está ajustado para los grados de libertad.

Los grados de libertad para la prueba de significancia $\mathrm{F}$ son $(\mathrm{k}-1, \mathrm{n}-\mathrm{k})$, donde $\mathrm{k}$ es el número de parámetros estimados (3) y $n=12$. Valores críticos al $5 \%$ respectivamente: $(3,11)=3.59,(2,11)=3.98$.

S.E.R: es el error estándar de la regresión, y D.W. es el estadístico Durbin-Watson.

Como se puede ver en el cuadro 6, es importante tomar en cuenta la correlación entre IMP y MUS. Para muchas industrias la elasticidad con respecto a IMP se vuelve significativa y mayor una vez que se excluye a MUS. Adicionalmente, para las industrias del papel, plástico, objetos de barro, loza y porcelana, cemento, maquinaria y productos metálicos (CIIU 341, 356, 361, 369, 381 y 385) y para el agregado manufacturero (CIIU 3), la elasticidad RULC se vuelve significativa después de excluir a MUS. Nótese que el coeficiente de determinación R2 (ajustado para grados de libertad) y el S.E.R en todos estos casos decrecen con la exclusión de MUS. En otras palabras, el ingreso extranjero (aproximado por las importaciones de E.U.A., MUS) parece ser un determinante importante de las exportaciones mexicanas.

Las elasticidades con respecto a RULC, son positivas y significativas para 11 de las 18 industrias. Como se verá más adelante, las industrias para las que esta elasticidad no es positiva, son distintas en cuanto a su desempeño exportador.

Las elasticidades con respecto a IMP y MUS son positivas y estadísticamente significativas para casi todas las industrias. Pero las excepciones son muy relevantes. Para las industrias textil y del vestido, del calzado y de la madera (CIIU 321, 324 y 33), la elasticidad de IMP es negativa y significativa. La única elasticidad de MUS negativa y significativa se obtiene de la industria del hierro y el acero (CIIU- 371).

La importancia del análisis por sector queda manifiesta al establecer si las elasticidades de las exportaciones con respecto a las variables explicativas son estadísticamente iguales para los distintos sectores. Al llevar a cabo la prueba de igualdad de todos los coeficientes se obtiene un valor de 360.0 que es muy superior al valor crítico. La prueba de que las elasticidades con respecto a RULC son iguales también se rechaza, pero en este caso el valor del estadístico es mucho menor: 65.6. De esta manera podemos concluir que las elasticidades son significativamente distintas para el conjunto de los sectores.

Como en el caso de los resultados de los cinco sectores considerados para el periodo 1970-1994, las pruebas realizadas no dejan duda de las diferencias estadísticas de las elasticidades. Sin embargo, al llevar a cabo estas pruebas para un subgrupo de sectores los resultados son distintos. Por ejemplo, podemos preguntar si la elasticidad con respecto a RULC es igual para aquellos sectores para los que esta elasticidad es estadísticamente mayor a cero (11 de los 18 sectores). Al llevar a cabo esta prueba se obtiene un valor de 6.7 que es apenas superior al valor crítico. En otras palabras, si bien no se puede considerar que todos los sectores respondan de igual manera a los cambios de las variables explicativas, al restringir estas pruebas para un número de sectores, las elasticidades no parecen ser muy distintas.

Antes de analizar más a fondo los resultados obtenidos, es necesario verificar su solidez, como se hizo con los resultados del periodo 1970-1994. En primer lugar se estimó el modelo con el método de Johansen y Juselius. Para las industrias de objetos de barro, loza y porcelana, del hierro y acero y equipo profesional (CIIU 361, 371 y 385) los vectores obtenidos son muy similares a los que se obtienen por M.C.O., pero la hipótesis de cointegración se rechaza, aún al 10\%. Para los sectores de los alimentos, del cuero y del hule (CIIU 311, 323 y 355) los resultados indican que se acepta la 
hipótesis de cointegración, y aunque los vectores obtenidos son distintos a los que se obtienen por M.C.O., ello no afecta el agrupamiento de industrias que se presenta más adelante. Para los sectores del calzado y productos de madera (CIIU 324 y 33) los vectores de cointegración son distintos a los obtenidos por M.C.O. por lo cual es recomendable tener cautela en la interpretación de los resultados para estas industrias. Finalmente, para el resto de las industrias (bebidas, textiles, papel, químicos, plásticos, vidrio, cemento, maquinaria y aparatos metálicos, maquinaria y equipo eléctrico, y equipo de transporte) los resultados son muy similares a los obtenidos por M.C.O . y la hipótesis de cointegración se acepta al 5\% o 10\%.

En segundo lugar se analizó la matriz de correlación de los coeficientes de los residuales, y se encontró que presenta varios coeficientes altos. La prueba propuesta por Breusch y Pagan (1980), introducida anteriormente, resultó en un valor de 360.2, que es altamente significativo a un nivel del $5 \%$. Esto sugiere que hay una fuerte correlación de los residuales en las ecuaciones. No fue posible obtener estimaciones utilizando el método S.U.R., ya que se obtiene una matriz casi singular en el proceso. Como se muestra en G reene (1993), la eficiencia obtenida utilizando el método S.U.R. está positivamente relacionada con el grado de correlación de los residuales, que es alto en este caso, pero negativamente relacionada con la correlación de las variables explicativas en las ecuaciones, que es también alta en este caso. (Las regresiones utilizando RP para CIIU 311, 371 y 384 fueron muy similares a las que se obtuvieron utilizando RULC y no son presentadas.) No es posible saber si es posible obtener estimadores más eficientes, ya que estos dos factores actuan en direcciones opuestas. En cualquier caso los resultados deben ser tomados con cautela, ya que algunos factores omitidos podrían ser importantes en la explicación del crecimiento de las exportaciones.

En tercer lugar, con respecto al uso de RP como aproximación del tipo de cambio real, los resultados (mostrados en el apéndice, cuadro A-2) son diferentes para pocas industrias. Para el agregado manufacturero (CIIU-3), las elasticidades-punto no difieren, pero el error estándar de la variable de tipo de cambio real (RP) es ahora insignificativa aún al 10\%. Este es también el caso de la industria del plástico (356). Para la industria del papel (341) las elasticidades-punto son muy similares pero no son significativas cuando se utiliza RP. Y finalmente para la industria de la maquinaria y productos metálicos (381) la elasticidad con respecto a RP es significativa al 10\%. En general, parece que el uso de RP en lugar de RULC produce pequeñas variaciones en los resultados obtenidos y sólo para pocas industrias. Por lo tanto, las conclusiones que se obtienen utilizando RULC no varían por esta consideración.

Finalmente, los resultados que se obtienen al utilizar CAP como indicador de capacidad de oferta doméstica en lugar de IMP se presentan en el cuadro A-4. Los resultados sí difieren para las industrias de los textiles y de los productos de madera (CIIU 321 y 33). Como puede verse en ese cuadro la sustitución de CAP por IMP hace que la elasticidad con respecto a RULC sea positiva y estadísticamente significativa, y además, en el caso de los productos de madera, la elasticidad con respecto a MUS es ahora negativa aunque sólo significativa al 10\%.

Para una mejor apreciación de los resultados de la regresión, necesitamos calcular la contribución de cada variable explicativa en el crecimiento de las exportaciones para cada industria. Con este fin, la elasticidad obtenida es multiplicada por la tasa de crecimiento promedio anual de las variables. Los resultados se presentan en el cuadro 7.

La primera y segunda columnas del cuadro 7 contienen el número de industria CIIU y las variables del modelo. En la tercera columna se muestran las elasticidades de las exportaciones con respecto a cada variable independiente. Esas elasticidades se obtienen del cuadro 6. Si la exclusión de MUS no tiene efecto en la elasticidad de RULC, y se obtiene un mejor ajuste incluyendo MUS, entonces el modelo seleccionado para este ejercicio sería el que incluye a MUS. Las elasticidades no significativas han sido igualadas a cero. La columna (4) contiene la tasa de crecimiento promedio anual de cada variable para cada industria. Esta tasa de crecimiento se calculó como un promedio aritmético simple de las tasas de crecimiento anuales entre 1983 y 1994. La columna (5) es el resultado de multiplicar 
las columnas (3) y (4). El último renglón de esta columna para cada industria representa la suma de productos, e.j., la tasa pronosticada de crecimiento promedio anual de las exportaciones. Finalmente, en la última columna se muestra la tasa de crecimiento promedio anual observada. 
Cuadro 7

Crecimiento observado y pronosticado de las exportaciones, 1983-1994

\begin{tabular}{|c|c|c|c|c|c|}
\hline $\begin{array}{l}\text { Industria } \\
\text { C.I.I.U. } \\
\text { (1) }\end{array}$ & $\begin{array}{l}\text { Variable } \\
\text { (2) }\end{array}$ & $\begin{array}{c}\text { Elasticidad } \\
\text { obtenida } \\
\text { (3) }\end{array}$ & $\begin{array}{c}\text { Tasa de } \\
\text { crecimiento } \\
\text { promedio anual de } \\
\text { la variable, 83-94 } \\
\text { (4) }\end{array}$ & $\begin{array}{l}\text { Crecimiento de } \\
\text { exportaciones } \\
\text { explicado por la } \\
\text { variable } \\
\text { (5) }\end{array}$ & $\begin{array}{c}\text { Crecimiento } \\
\text { observado de } \\
\text { exportaciones } \\
\text { (6) }\end{array}$ \\
\hline $\begin{array}{c}3 \\
\text { Total Manufacturero }\end{array}$ & \begin{tabular}{|cc} 
& RULC \\
& IMP \\
& \\
& MUS \\
SUM &
\end{tabular} & $\begin{array}{l}0.73 \\
4.09\end{array}$ & $\begin{array}{l}-1.67 \\
2.83 \\
8.38\end{array}$ & $\begin{array}{r}-1.22 \\
11.58 \\
10.36\end{array}$ & 12.08 \\
\hline $\begin{array}{c}311 \\
\text { Alimentos }\end{array}$ & 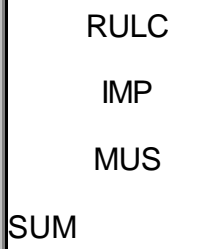 & $\begin{array}{l}0.62 \\
0.0 \\
0.0\end{array}$ & $\begin{array}{l}-1.66 \\
1.71 \\
2.91\end{array}$ & $\begin{array}{l}-1.03 \\
-1.03\end{array}$ & 0.5 \\
\hline $\begin{array}{c}313 \\
\text { Bebidas }\end{array}$ & \begin{tabular}{|ll} 
& RULC \\
& IMP \\
& \\
& MUS \\
SUM &
\end{tabular} & $\begin{array}{l}1.6 \\
3.0 \\
2.5\end{array}$ & $\begin{array}{l}-3.73 \\
3.76 \\
2.42\end{array}$ & $\begin{array}{l}-5.97 \\
11.28 \\
6.04 \\
11.35\end{array}$ & 13.11 \\
\hline $\begin{array}{l}321 \\
\begin{array}{l}\text { Textiles y prendas } \\
\text { de vestir }\end{array}\end{array}$ & \begin{tabular}{|cc} 
& RULC \\
& IMP \\
& \\
& MUS \\
SUM &
\end{tabular} & $\begin{array}{c}0.0 \\
-3.40 \\
0.97\end{array}$ & $\begin{array}{l}-1.9 \\
-0.88 \\
9.93\end{array}$ & $\begin{array}{c}0.0 \\
2.99 \\
9.63 \\
12.62\end{array}$ & 12.91 \\
\hline $\begin{array}{l}323 \\
\text { Cuero }\end{array}$ & \begin{tabular}{|cc} 
& RULC \\
& IMP \\
& MUS \\
& \\
SUM &
\end{tabular} & $\begin{array}{r}0.0 \\
0.0 \\
4.50\end{array}$ & $\begin{array}{r}0.68 \\
-1.13 \\
5.47\end{array}$ & $\begin{array}{c}0.0 \\
0.0 \\
24.61 \\
24.61\end{array}$ & 19.02 \\
\hline $\begin{array}{l}324 \\
\text { Calzado }\end{array}$ & \begin{tabular}{|cc} 
& RULC \\
& IMP \\
& \\
& MUS \\
SUM &
\end{tabular} & $\begin{array}{l}0.0 \\
-2.2 \\
1.2\end{array}$ & $\begin{array}{l}-3.16 \\
-4.97 \\
5.04\end{array}$ & $\begin{array}{c}0.0 \\
10.94 \\
6.05 \\
16.99\end{array}$ & 15.91 \\
\hline $\begin{array}{c}33 \\
\text { Madera }\end{array}$ & \begin{tabular}{|cc} 
& RULC \\
& IMP \\
& \\
& MUS \\
SUM &
\end{tabular} & $\begin{array}{r}0.0 \\
-4.3 \\
1.12\end{array}$ & $\begin{array}{l}-1.53 \\
-0.12 \\
4.41\end{array}$ & $\begin{array}{c}0.0 \\
0.54 \\
4.94 \\
5.47\end{array}$ & 6.21 \\
\hline $\begin{array}{l}341 \\
\text { Papel }\end{array}$ & $\begin{array}{l}\text { RULC } \\
\text { IMP } \\
\text { MUS }\end{array}$ & $\begin{array}{l}1.95 \\
4.09 \\
0.0\end{array}$ & $\begin{array}{l}-0.97 \\
1.97 \\
4.43\end{array}$ & $\begin{array}{c}-1.89 \\
8.06 \\
0.0\end{array}$ & 8.73 \\
\hline
\end{tabular}




\begin{tabular}{|c|c|c|c|c|c|}
\hline & SUM & & & 6.17 & \\
\hline $\begin{array}{c}351 \\
\text { Químicos }\end{array}$ & 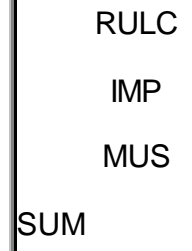 & $\begin{array}{l}0.0 \\
1.95 \\
0.62\end{array}$ & $\begin{array}{l}-3.18 \\
3.47 \\
9.40\end{array}$ & $\begin{array}{c}0.0 \\
6.78 \\
5.83 \\
12.6\end{array}$ & 10.89 \\
\hline $\begin{array}{l}355 \\
\text { Hule }\end{array}$ & $\begin{array}{ll} & \text { RULC } \\
& \text { IMP } \\
& \text { MUS } \\
\text { SUM } & \end{array}$ & $\begin{array}{l}1.18 \\
0.0 \\
1.41\end{array}$ & $\begin{array}{l}1.30 \\
2.00 \\
11.52\end{array}$ & $\begin{array}{c}1.53 \\
0.0 \\
16.25 \\
17.78\end{array}$ & 14.28 \\
\hline $\begin{array}{c}356 \\
\text { Plásticos }\end{array}$ & 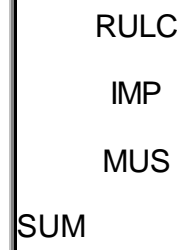 & $\begin{array}{l}0.75 \\
3.2 \\
0.0\end{array}$ & $\begin{array}{r}2.03 \\
5.19 \\
12.68\end{array}$ & $\begin{array}{c}1.52 \\
16.62 \\
0.0 \\
18.15\end{array}$ & 17.52 \\
\hline $\begin{array}{l}361 \\
\text { Objetos de barro, } \\
\text { loza y porcelana }\end{array}$ & 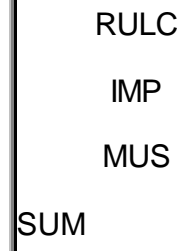 & $\begin{array}{l}1.03 \\
5.9 \\
0.0\end{array}$ & $\begin{array}{c}-1.24 \\
3.03 \\
5.6\end{array}$ & $\begin{array}{c}-1.28 \\
17.87 \\
0.0 \\
16.59\end{array}$ & 15.59 \\
\hline $\begin{array}{r}362 \\
\text { Vidrio }\end{array}$ & 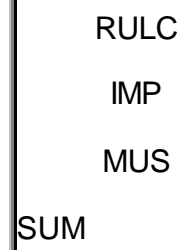 & $\begin{array}{c}0.0 \\
1.20 \\
1.20\end{array}$ & $\begin{array}{l}0.75 \\
3.69 \\
8.24\end{array}$ & $\begin{array}{c}0.0 \\
4.43 \\
9.88 \\
14.32\end{array}$ & 12.86 \\
\hline $\begin{array}{c}369 \\
\text { Cemento y } \\
\text { otros minerales no } \\
\text { metálicos }\end{array}$ & 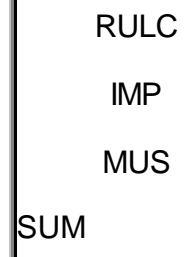 & $\begin{array}{c}0.53 \\
1.02 \\
0.0\end{array}$ & $\begin{array}{l}5.60 \\
4.09 \\
9.20\end{array}$ & $\begin{array}{r}2.97 \\
4.17 \\
0.0 \\
7.14\end{array}$ & 8.12 \\
\hline $\begin{array}{c}371 \\
\text { Hierro y acero }\end{array}$ & 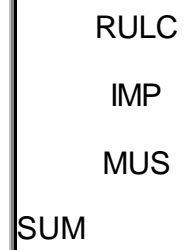 & $\begin{array}{c}1.1 \\
3.7 \\
-0.90\end{array}$ & $\begin{array}{l}2.65 \\
3.61 \\
6.08\end{array}$ & $\begin{array}{r}2.92 \\
13.35 \\
-5.47 \\
10.80\end{array}$ & 10.62 \\
\hline $\begin{array}{c}381 \\
\text { Maquinaria y } \\
\text { productos metálicos }\end{array}$ & 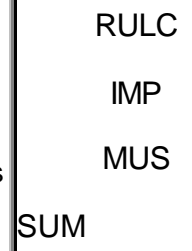 & $\begin{array}{c}1.81 \\
6.41 \\
0.0\end{array}$ & $\begin{array}{c}-3.73 \\
3.59 \\
12.38\end{array}$ & $\begin{array}{c}-6.75 \\
23.01 \\
0 \\
16.26\end{array}$ & 18.80 \\
\hline $\begin{array}{c}383 \\
\text { Maquinaria eléctrica }\end{array}$ & $\begin{array}{l}\text { RULC } \\
\text { IMP }\end{array}$ & $\begin{array}{l}0.0 \\
0.0\end{array}$ & $\begin{array}{l}-2.41 \\
5.29\end{array}$ & $\begin{array}{l}0.0 \\
0.0\end{array}$ & 22.01 \\
\hline
\end{tabular}




\begin{tabular}{|c|c|c|c|c|c|}
\hline & SUM & 1.6 & 10.78 & $\begin{array}{l}17.25 \\
17.25\end{array}$ & \\
\hline $\begin{array}{c}384 \\
\text { Equipo de } \\
\text { transporte }\end{array}$ & 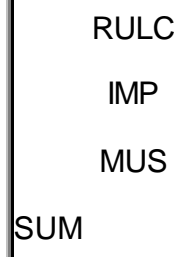 & $\begin{array}{l}0.40 \\
0.90 \\
1.00\end{array}$ & $\begin{array}{l}2.88 \\
9.15 \\
5.28\end{array}$ & $\begin{array}{c}1.15 \\
8.23 \\
5.28 \\
14.66\end{array}$ & 15.42 \\
\hline $\begin{array}{c}385 \\
\begin{array}{c}\text { Equipo profesional y } \\
\text { científico }\end{array}\end{array}$ & $\begin{array}{ll} & \text { RULC } \\
& \text { IMP } \\
& \text { MUS } \\
\text { SUM } & \end{array}$ & $\begin{array}{r}0.56 \\
4.60 \\
0.0\end{array}$ & $\begin{array}{l}2.06 \\
2.86 \\
12.79\end{array}$ & $\begin{array}{c}1.13 \\
13.11 \\
0.0 \\
14.25\end{array}$ & 16.96 \\
\hline
\end{tabular}

De acuerdo con la contribución de las variables explicativas al crecimiento de las exportaciones de 
cada industria, se pueden identificar cinco grupos. En primer lugar, para la industria alimenticia (CIIU-311), la única variable significativa es RULC. D urante el periodo de análisis (1983-1994) esta variable decreció (apreciación) a una tasa de - 1.7 anual promedio, de manera que el modelo predice un crecimiento negativo de las exportaciones para esta industria (tasa anual promedio de -1.0\%), mientras que las exportaciones observadas crecieron a una tasa de $0.5 \%$ promedio anual.

El segundo grupo de industrias es similar al primero en que la elasticidad con respecto a RULC es positiva y en que durante el periodo hubo una apreciación de RULC (una tasa anual de crecimiento negativa de esta variable). Las exportaciones de estas industrias deberían haberse contraído, ceteris paribus. Sin embargo, la elasticidad con respecto a IMP, MUS o ambas es positiva, contribuyendo a la expansión de las exportaciones, ya que estas variables crecieron durante el periodo. Las industrias del papel, las bebidas, los objetos de barro, loza y porcelana y de la maquinaria y productos metálicos (CIIU 341,313,361 y 381) pertenecen a este segundo grupo.

Un tercer grupo, formado por las industrias textil y del vestido, del calzado y de la madera (CIIU 321,324 y 33), tienen en común una tasa anual promedio negativa de IMP y también una elasticidad negativa con respecto a esa variable. También tienen en común una elasticidad RULC no significativa. Las exportaciones crecieron mientras la capacidad de oferta se estaba contrayendo, pero la elasticidad positiva con respecto a la demanda extranjera (MUS) explica la expansión de las exportaciones de esas industrias. (Es pertinente recordar que al usar CAP como indicador de la capacidad, la elasticidad con respecto a RULC es positiva y significativa para las industrias de los textiles y de la madera (CIIU 321 y 33) como se muestra en el cuadro A-4. Sin embargo, esto no altera el resultado que se obtiene con respecto a la elasticidad de la capacidad de oferta y la contribución que esta variable hizo al crecimiento de las exportaciones, ya que CAP decreció durante el período de estimación para estas industrias.)

La explicación del crecimiento de las exportaciones para el cuarto grupo, formado por las industrias del cuero, los químicos, el vidrio y la maquinaria eléctrica (CIIU 323, 351, 362 y 383), está relacionada con la expansión de IMP, MUS o ambas. D e manera similar al tercer grupo, RULC no es estadísticamente significativo para estas industrias.

Un quinto grupo está formado por las industrias del hule, el plástico, el cemento, hierro y acero, del equipo de transporte y del equipo profesional y científico (CIIU 355, 356, 369, 371, 384 y 385). Para este grupo la elasticidad con respecto a RULC es positiva, como en el caso del primero y segundo grupos, pero durante el periodo, en contraste con las industrias de esos grupos, RULC creció (depreciación), contribuyendo positivamente al crecimiento de las exportaciones, adicionalmente al efecto positivo de IMP, MUS o ambas.

Finalmente, para las industrias de imprenta y editoriales, de refinería del petróleo, de metales no ferrosos y de otras manufacturas (CIIU 342, 353-354, 372 y 39), los resultados de la regresión no fueron satisfactorios y no se presentan. Estas industrias forman un sexto grupo.

Un cuadro sencillo ilustra este agrupamiento de industrias. 
Clasificación de las industrias de acuerdo a los resultados; 1983-1994

\begin{tabular}{|c|c|c|c|c|c|c|c|}
\hline \multicolumn{2}{|r|}{ Industrias } & \multicolumn{2}{|c|}{ RULC } & \multicolumn{2}{|c|}{$\mathrm{IMP}$} & \multicolumn{2}{|c|}{ MUS } \\
\hline Grupo & CIIU & Elasticidad & tcpa & Elasticidad & tcpa & Elasticidad & tcpa \\
\hline I & 311 & + & - & & & & \\
\hline ॥ & $313,341,361,381$ & + & - & + & + & + & + \\
\hline III & $321,324,33$ & & & - & - & + & + \\
\hline IV & $323,351,362,383$ & & & + & + & + & + \\
\hline $\mathrm{V}$ & $355,356,369371,384,385$ & + & + & + & + & + & + \\
\hline $\mathrm{Vl}$ & $342,353-354,372,39$ & & & & & & \\
\hline
\end{tabular}

tcpa es la tasa del crecimiento promedio anual durante el periodo.

D e esta manera, el signo de las elasticidades y la evolución de las variables explicativas durante el periodo de análisis nos ayudan a identificar a estos cinco grupos de industrias. Surge así una visión clara de los distintos determinantes de las exportaciones.

Es ilustrativo ver cómo se comportan las industrias durante el periodo de acuerdo con las variables utilizadas en el análisis. En el cuadro 9 se presentan los promedios simples de la tasa de crecimiento promedio anual de las variables explicativas y de la variable dependiente de las industrias en cada grupo. Para un análisis más detallado también se presentan los componentes de las variaciones de RULC (ROL y RWL), a pesar de que no fueron utilizados en el análisis de la regresión. Dada la importancia especial de CIIU-384, la industria automotriz, esta industria también se presenta individualmente.

Cuadro 9

Promedio de la tasa de crecimiento anual promedio de las variables para cada grupo de industrias, 1983-1994

\begin{tabular}{|c|c|c|c|c|c|c|}
\hline & $\mathrm{X}$ & $\mathrm{IMP}$ & $\mathrm{MUS}$ & $\mathrm{RULC}$ & $\mathrm{ROL}$ 1/ & RWL 2/ \\
\hline I & 0.5 & 1.7 & 2.9 & -1.7 & -0.2 & -1.9 \\
\hline $\mathrm{II}$ & 14.1 & 3.1 & 6.2 & -2.4 & -0.6 & -3.0 \\
\hline III & 11.7 & -2.0 & 6.5 & -2.1 & 1.4 & -0.7 \\
\hline IV & 16.2 & 2.8 & 8.5 & -1.0 & -0.9 & -1.8 \\
\hline V & 13.8 & 4.5 & 9.6 & 2.8 & -4.4 & -1.5 \\
\hline De las que: & 15.4 & 9.1 & 5.3 & 2.9 & -6.4 & -3.5 \\
\hline Automotriz & 13.5 & 3.5 & 10.5 & 2.7 & -4.0 & -1.1 \\
\hline Otras & 5.4 & 3.8 & 7.3 & -1.7 & -0.7 & -2.3 \\
\hline VI & & & & & & \\
\hline
\end{tabular}

1/ ROL es el producto relativo (E.U.A./ México) por trabajador. Un número negativo significa que la productividad está creciendo más rápido en México y por lo tanto una mejor posición competitiva del país.

2/ RWL es el salario relativo (E.U.A./ México) por trabajador en la misma moneda. Un número positivo significa que los salarios por trabajador están creciendo más rápido en E.U.A., y por lo 
tanto una mejor posición competitiva de costos para México.

Hay que notar en primer lugar que el comportamiento de las exportaciones es claramente superior para algunos grupos, mientras que el grupo I (CIIU-311) y aquéllos no considerados en el análisis de la regresión (grupo VI), tuvieron un comportamiento relativamente bajo. Para los otros cuatro grupos, el crecimiento anual promedio es más o menos similar. (Se podría esperar encontrar un mayor crecimiento de las exportaciones para el grupo $\mathrm{V}$, ya que la productividad creció más rápido. Sin embargo, hay otros factores que intervienen, como las otras variables explicativas. Por ejemplo, puede ser que aunque mejore la productividad, la demanda externa no se expanda lo suficiente. Adicionalmente, aún en este nivel de agregación pueden existir experiencias contrastantes al interior de una industria manufacturera.)

Hay algunas diferencias importantes concernientes a las variables explicativas (IMP, MUS y RULC). La expansión de la capacidad doméstica (IMP) es mayor para los grupos V (principalmente explicada por la extraordinaria expansión de IMP de la industria automotriz) y VI, y negativa para el grupo III.

El crecimiento de la demanda externa (MUS) es notablemente mayor para los grupos IV y V. Sin embargo, los promedios simples presentados en el cuadro 9 esconden diferencias importantes. Las importaciones de E.U.A. crecieron especialmente rápido para CIIU-381, 383 y 385 (incluídos en los grupos II, IV y V, respectivamente).

Con respecto a RULC, la tasa de crecimiento promedio es negativa para todos los grupos con excepción del V, lo que significa que desde 1983 hasta 1994 hubo una apreciación del tipo de cambio real para la mayoría de las industrias. Pero para el grupo V, RULC continuó depreciándose. Ahora bien, de acuerdo con las dos últimas columnas del cuadro 9, el proceso de depreciación está explicado por el rápido incremento de la productividad del trabajo (ROL), ya que el deterioro de los salarios relativos (RWL) no parece ser muy distintos al resto de los grupos.

Sin duda este es el resultado más importante e interesante del análisis. Para las industrias de los grupos I, II y V el crecimiento de las exportaciones está relacionado con el comportamiento de los costos unitarios de la mano de obra. Pero solamente para el grupo $\mathrm{V}$ el crecimiento de la productividad relativa del trabajo en favor de México (ROL) más que compensó el crecimiento de los salarios relativos en México (RWL), y de esta manera el crecimiento de RULC contribuyó positivamente al aumento de las exportaciones. Son precisamente las industrias del grupo V las que muestran el mayor aumento de la productividad de la mano de obra dentro de la industria manufacturera de México.

\section{Resumen y conclusiones.}

En este artículo se llevó a cabo un análisis econométrico con el fin de establecer si los determinantes del crecimiento de las exportaciones de los sectores manufactureros son similares. Se utilizó para este propósito una ecuación para las cantidades exportadas. D os indicadores alternativos del tipo de cambio real fueron usados: precios relativos al productor y costos unitarios relativos de la mano de obra. El periodo de estimación fue 1970-1994 para algunas industrias y para el total manufacturero, y casi el total de las industrias fueron consideradas para el periodo 1983-1994.

Los resultados son efectivamente distintos para las industrias manufactureras. Para la década de 1970, el tipo de cambio real no parece haber jugado un papel importante para el agregado manufacturero y para algunas industrias. Sin embargo, para otras industrias esta variable influyó el comportamiento de las exportaciones. Se encontró que después de 1983 las exportaciones se volvieron mas elásticas con respecto al ingreso extranjero y/ o a la capacidad de oferta doméstica, lo que puede explicarse por la fuerte depreciación real que tuvo lugar en 1982 y 1983, y por el cambio gradual en la política comercial, que inicialmente permitió a las empresas importar libremente insumos para el proceso de exportación. Se argumentó que estos dos hechos volvieron a la 
exportación una actividad más rentable.

D espués de 1983 los determinantes del crecimiento de las exportaciones son también distintos para las distintas industrias. Se mostró que las exportaciones de algunas industrias son sensibles a variaciones del tipo de cambio real. Pero más importante aún es que se identificaron diferentes contribuciones de la variable RULC. Se mostró que para aquellas industrias para las cuales la productividad laboral creció más rápido, las exportaciones crecieron relativamente más rápido, como consecuencia.

La conclusión principal del trabajo es que los determinantes del crecimiento de las exportaciones no son los mismos para las industrias. Esto justifica que desde la perspectiva de la política económica sea necesario considerar que factores explican estos contrastes. Resulta de vital importancia considerar la situación de algunas industrias, como por ejemplo las de productos textiles y de prendas de vestir, calzado y cuero, para las cuales las altas tasas de crecimiento de las exportaciones no parecen ser explicadas por una dinámica virtuosa que va de la productividad hacia las exportaciones. Por el contrario, pareciera que las exportaciones se expandieron a la par que la producción de estas industrias se contrajo.

Una limitante importante del análisis es que aún al nivel de agregación utilizado en este trabajo existen experiencias contrastantes al interior de algunas industrias. Por ejemplo, dentro del sector de las bebidas, las empresas productoras de cerveza muestran una dinámica de crecimiento de exportaciones con fuertes incrementos de la productividad. En otras industrias esta mezcla de sectores también es evidente. Pero esta limitante no le resta importancia al agrupamiento que se presenta en este trabajo, ya que ilustra en qué industrias los rezagos son más o menos importantes. 
Cuadro A-1 Comparación de los Resultados de la Regresión, 1970-1994

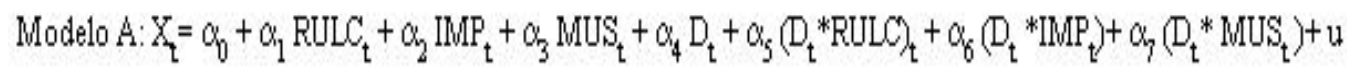

Modelo $\mathrm{B}: \mathrm{X}_{\mathrm{t}}=\alpha_{0}+\alpha_{1} \mathrm{RP}_{\mathrm{t}}+\alpha_{2} \mathrm{MP}_{\mathrm{t}}+\alpha_{3} \mathrm{MUS}_{\mathrm{t}}+\alpha_{4} \mathrm{D}_{\mathrm{t}}+\alpha_{5}\left(\mathrm{D}_{\mathrm{t}} * \mathrm{RP}\right)_{\mathrm{t}}+\alpha_{6}\left(\mathrm{D}_{\mathrm{t}} * \mathrm{IMP}_{\mathrm{t}}+\alpha_{7}\left(\mathrm{D}_{\mathrm{t}} * \mathrm{MUS} \mathrm{S}_{\mathrm{t}}\right)+u_{\mathrm{t}}\right.$

\begin{tabular}{|c|c|c|c|c|c|c|}
\hline & \multicolumn{2}{|c|}{ CIIU-3 } & \multicolumn{2}{|c|}{ CIIU-351 } & \multicolumn{2}{|c|}{ CIIU-362 } \\
\hline & Modelo A & Modelo B & Modelo A & Modelo B & Modelo A & Modelo E \\
\hline \multirow{2}{*}{0} & 2.9 & 1.59 & $9.0 *$ & $2.86^{*}$ & 0.81 & 0.69 \\
\hline & (1.5) & $(0.90)$ & (3.5) & (3.17) & $(0.8)$ & $(0.53)$ \\
\hline \multirow{2}{*}{1} & $-0.72^{*}$ & "-0.59 & $-1.0^{*}$ & ( & $-0.29^{* * *}$ & (-0.24 \\
\hline & (2.0) & (1.51) & (2.8) & (1.58) & (1.80) & (1.20) \\
\hline \multirow{2}{*}{2} & -0.60 & $\begin{array}{c}.0 .29 \\
\end{array}$ & $-1.1^{*}$ & 2.0 .06 & $0.86 *$ & $0.91 *$ \\
\hline & $(1.63)$ & $(0.92)$ & (3.5) & $(0.22)$ & (3.7) & (3.89) \\
\hline \multirow{2}{*}{3} & $1.65^{*}$ & $1.52 *$ & $1.15^{*}$ & $0.87^{*}$ & 0.28 & 0.21 \\
\hline & $(4.85)$ & $(4.45)$ & $(5.49)$ & (2.96) & (1.1) & $(0.89)$ \\
\hline \multirow{2}{*}{4} & $-12.2 *$ & $-10.37 *$ & $-176^{*}$ & $-10.52 *$ & $-6.3^{*}$ & $-6.08 *$ \\
\hline & (3.1) & (2.83) & (4.4) & (3.58) & (2.9) & $(4.59)$ \\
\hline \multirow{2}{*}{$s$} & $0.90^{*}$ & 0.79 & $1.24 *$ & $\begin{array}{l}0.71 \\
\end{array}$ & 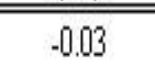 & $\begin{array}{c}-0.03 \\
\end{array}$ \\
\hline & (2.1) & $(1.56)$ & (2.9) & $(1.61)$ & (0.12) & $(0.85)$ \\
\hline \multirow{2}{*}{6} & $2.48 *$ & $200 \%$ & $3.1^{*}$ & $1.76^{*}$ & 0.34 & 0.23 \\
\hline & (3.0) & (2.87) & (4.1) & $(2.25)$ & $(0.79)$ & $(0.54)$ \\
\hline \multirow{2}{*}{$?$} & -0.72 & -0.52 & -0.5 & -0.21 & $1.1^{*}$ & $1.14^{*}$ \\
\hline & (1.6) & (1.23) & (1.4) & $(0.47)$ & (3.01) & (2.74) \\
\hline
\end{tabular}

*Implica que el coeficiente es significativo a $5 \%$, ** a un $10 \%$. 
Cuadro A-2 Comparación de los Resultados de la Regresión, 1983-1994

Modelo $A: X_{2}=a_{0}+a_{1} \operatorname{RULC}_{t}+a_{2} \operatorname{MP}_{t}+a_{3} \operatorname{MUS}_{t}+u_{t}$

Modelo $\mathrm{B}: \mathrm{X}_{\mathrm{t}}=\mathrm{a}_{0}+\mathrm{a}_{1} \mathrm{RP}_{\mathrm{t}}+\mathrm{a}_{2} \mathrm{MMP}_{\mathrm{t}}+\mathrm{a}_{3} \mathrm{MUS}_{\mathrm{t}}+\mathrm{u}_{\mathrm{t}}$

\begin{tabular}{|c|c|c|c|c|c|c|c|c|c|c|}
\hline & \multicolumn{2}{|c|}{ CIIU 3} & \multicolumn{2}{|c|}{ CIIU 323} & \multicolumn{2}{|c|}{ CIIU 33} & \multicolumn{2}{|c|}{ CIIU 341} & \multicolumn{2}{|c|}{ CIIU 355} \\
\hline Parámetro & Modelo A & Modelo B & Modelo A & Modelo B & Modelo A & Modelo B & Modelo A & Modelo B & Modelo A & \begin{tabular}{|c} 
Modelo \\
B
\end{tabular} \\
\hline \multirow{2}{*}{0} & $-17.5^{*}$ & $-16.1 *$ & $-20.1 *$ & $-21.0 *$ & $18.76^{* * *}$ & $18.96^{* *}$ & $-22.7^{*}$ & -10.65 & 12.0 & 0.45 \\
\hline & (5.2) & (3.0) & (3.4) & (4.0) & (2.07) & (2.18) & (2.8) & $(1.48)$ & $(1.45)$ & $(0.05)$ \\
\hline \multirow{4}{*}{1} & & & & & & & & & $1.18^{* * *}$ & $2.48 *$ \\
\hline & $0.73^{*}$ & 0.70 & -0.25 & -0.80 & 0.06 & -0.1 & $1.95 *$ & 1.59 & & \\
\hline & 045 & 14 & 0.537 & 1700 & 014 & 027 & 060 & $(157$ & (L1) & (L1) \\
\hline & & & & & & & & & (2.1) & $(2.27)$ \\
\hline \multirow{2}{*}{2} & $4.09^{*}$ & 3.9 & 0.83 & 1.07 & -4.27 & $-4.2^{*}$ & $4.09^{*}$ & 2.02 & $-4.0 * *$ & -2.84 \\
\hline & $(8.48)$ & $(6.8)^{*}$ & (0.9) & $(1.22)$ & $(1.91) * *$ & (2.35) & (3.22) & (1.31) & $(1.90)$ & (1.4) \\
\hline \multirow{4}{*}{3} & \multirow{4}{*}{ - } & \multirow{4}{*}{ - } & $1.12 *$ & $4.97 *$ & $1.12^{*}$ & $1.16^{*}$ & \multirow{4}{*}{ - } & \multirow{4}{*}{ - } & \multirow{4}{*}{$1.41^{*}$} & \multirow{4}{*}{$\begin{array}{l}1.53^{*} \\
(3.15)\end{array}$} \\
\hline & & & (12) & (1) & (11) & (11) & & & & \\
\hline & & & & & & & & & & \\
\hline & & & (3.5) & (8.4) & (3.5) & (3.62) & & & & \\
\hline
\end{tabular}

\begin{tabular}{|c|c|c|c|c|c|c|c|c|c|c|}
\hline & \multicolumn{2}{|c|}{ CIIU 356} & \multicolumn{2}{|c|}{ CIIU 369} & \multicolumn{2}{|c|}{ CIIU 371} & \multicolumn{2}{|c|}{ CIIU 381} & \multicolumn{2}{|c|}{ CIIU 385} \\
\hline Parámetro & Modelo A & Modelo B & Modelo A & Modelo B & Modelo A & Modelo B & Modelo A & Modelo B & Modelo A & Modelo B \\
\hline \multirow{2}{*}{0} & $-13.3^{*}$ & $-15.4^{*}$ & -2.09 & $-11.76^{*}$ & $-11.8^{*}$ & $-16.29 *$ & $-31.3^{*}$ & $-23.8^{*}$ & $-18.5 *$ & $-29.9 *$ \\
\hline & (5.2) & (3.6) & $(1.25)$ & (2.78) & (4.3) & (3.1) & (2.9) & $(4.0)$ & (5.4) & (3.8) \\
\hline \multirow{4}{*}{1} & $0.75^{*}$ & 0.92 & & & & & & & & \\
\hline & & & $0.53^{*}$ & $1.02^{*}$ & $1.1^{*}$ & 1.49 & 1.83 & $1.96^{* *}$ & $0.55^{*}$ & $1.81^{* * *}$ \\
\hline & & & 1270 & 060 & 182 & 010 & 178 & & 020 & \\
\hline & (2.37) & (1.17) & & & & & & & & \\
\hline \multirow{4}{*}{2} & & & & & & & & & $4.59 *$ & $5.8^{*}$ \\
\hline & $3.2^{*}$ & $3.53^{*}$ & $1.02^{*}$ & $2.65^{*}$ & $37^{*}$ & $4.04 *$ & $6.41 *$ & $4.56^{*}$ & & \\
\hline & 100 & & & & & & & & (LI) & (L1) \\
\hline & & & & & & & & & & $(6.43)$ \\
\hline \multirow[b]{2}{*}{3} & & & & & $-0.9 * *$ & -0.68 & & & & \\
\hline & & & & & & (1.19) & & & & \\
\hline
\end{tabular}

*Implica que el coeficiente es significativo a1 $5 \%, * *$ al $10 \%$. 
Cuadro A-3 Comparación de los Resultados de la Regresión, 1970-1994

Modelo $A: X_{2}=a_{0}+a_{1} R U L C_{t}+a_{2} I M P_{t}+a_{3} M U S_{t}+a_{4} D_{t}+a_{5}\left(D_{t} * R U L C_{t}+a_{6}\left(D_{t} * M P_{t}\right)+a_{7}\left(D_{t} * M U S_{t}\right)+a\right.$

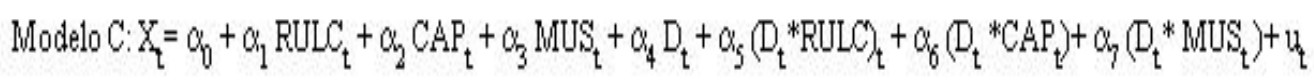

\begin{tabular}{|c|c|c|c|c|c|c|}
\hline & \multicolumn{2}{|c|}{ CIII-3 } & \multicolumn{2}{|c|}{ CIIJ-351 } & \multicolumn{2}{|c|}{ CIIU362 } \\
\hline & Modelo A & Modeloc & Modelo A & ModeloC & Modelo A & Modelo O \\
\hline \multirow{2}{*}{0} & 29 & 1.9 & $9.0 *$ & $8.1^{*}$ & 0.81 & $.2 .9 \%$ \\
\hline & (1.5) & (1.1) & (3.5) & (3.4) & (0.8) & (2.4) \\
\hline \multirow{2}{*}{1} & -0.72* & -0.51 & $-1.0 *$ & .0.8* & $-0.29 * *$ & 0.21 \\
\hline & (2.0) & $(1.75)$ & (2.8) & (2.0) & (1.80) & (1.2) \\
\hline \multirow{2}{*}{2} & -0.60 & -0.36 & $-1.1{ }^{*}$ & $-0.99 *$ & $0.86^{*}$ & $1.61^{*}$ \\
\hline & (1.63) & (1.0) & (3.5) & $(3.5)^{*}$ & (3.7) & (5.0) \\
\hline \multirow{2}{*}{3} & $1.65 *$ & $1.4 *$ & $1.15 *$ & $1.1{ }^{*}$ & 0.28 & -0.12 \\
\hline & $(485)$ & (4.5) & $(5.49)$ & (4.4) & (1.1) & (0.5) \\
\hline \multirow{2}{*}{4} & $-12.2 *$ & $.21 .1 \%$ & $.176^{*}$ & $.15 .9 *$ & $-6.3 *$ & -6.8 \\
\hline & (3.1) & $(4.2)$ & (4.4) & $(4.2)$ & (2.9) & (2.7) \\
\hline \multirow{2}{*}{5} & $0.90 *$ & $0.89 *$ & $1.24^{*}$ & $1.15 *$ & .0 .03 & 0.1 \\
\hline & (2.1) & $(2.4)^{*}$ & (2.9) & (2.8) & $(0.12)$ & (0.3) \\
\hline \multirow{2}{*}{6} & $2.48 *$ & $5.0^{*}$ & $3.1^{*}$ & $2.5 *$ & 0.34 & 0.9 \\
\hline & (3.0) & (3.9) & (4.1) & (3.0) & $(0.79)$ & (1.3) \\
\hline \multirow{2}{*}{$?$} & -0.72 & $.13^{*}$ & -0.5 & .0 .25 & $1.1 \%$ & $0.6^{* *}$ \\
\hline & (1.0) & (2.0) & (1.4) & $(0,7)$ & (301) & (1.8) \\
\hline
\end{tabular}

*Implica que el coeficiente es signrificativo a $5 \%$, ** a 1 10\%. 
Cuadro A-4 Comparación de los Resultados de la Regresión, 1983-1994

Modelo $A: X_{t}=a_{0}+a_{1} \operatorname{RULC}_{t}+a_{2} \operatorname{MPP}_{t}+a_{3} \operatorname{MUS}_{t}+u_{t}$

Modelo B: $\mathrm{X}_{\mathrm{t}}=\mathrm{a}_{0}+\mathrm{a}_{1} \mathrm{RULC}_{\mathrm{t}}+\mathrm{a}_{2} \mathrm{CAP}_{\mathrm{t}}+\mathrm{a}_{3} \mathrm{MUS}_{\mathrm{t}}+\mathrm{u}_{\mathrm{t}}$

\begin{tabular}{|c|c|c|c|c|c|c|c|c|c|c|}
\hline & \multicolumn{2}{|c|}{ CIIU 3} & \multicolumn{2}{|c|}{ CIIU 311} & \multicolumn{2}{|c|}{ CIIU 321} & \multicolumn{2}{|c|}{ CIIU 323} & \multicolumn{2}{|c|}{ CIIU 324} \\
\hline Parámetro & Modelo A & Modelo B & Modelo A & Modelo B & Modelo A & Modelo B & Modelo A & Modelo B & Modelo A & $\begin{array}{c}\text { Modelo } \\
\text { B }\end{array}$ \\
\hline \multirow{2}{*}{0} & $-17.5^{*}$ & $-20.7^{*}$ & -1.1 & -3.4 & $14.8^{* * *}$ & $28.6^{*}$ & $-20.1 *$ & -4.5 & 7.7 & 4.5 \\
\hline & (5.2) & (12.2) & (0.3) & (1.2) & (2.1) & (3.7) & (3.4) & (0.5) & (1.4) & (0.6) \\
\hline \multirow{2}{*}{1} & $0.73 *$ & $0.43 *$ & $0.62 *$ & $0.72 *$ & 0.15 & $1.0^{*}$ & -0.25 & 0.11 & 0.07 & 0.07 \\
\hline & (2.45) & (3.3) & (2.4) & (3.9) & $(0.5)$ & (3.1) & $(0.53)$ & $(0.2)$ & $(0.2)$ & (0.1) \\
\hline & $4.09 *$ & $5.1^{*}$ & 0.4 & 1.5 & $-3.4 *$ & $-6.9 *$ & 0.83 & $=2.0$ & $-2.2 *$ & $\begin{array}{l}-1.7 \\
\end{array}$ \\
\hline & $(8.48)$ & (18.8) & (0.4) & (1.0) & (2.3) & (3.9) & (0.9) & (1.1) & (2.3) & (1.1) \\
\hline \multirow{3}{*}{3} & \multirow{3}{*}{ - } & \multirow{3}{*}{ - } & \multirow{3}{*}{$\begin{array}{l}0.13 \\
(0.19)\end{array}$} & \multirow{3}{*}{$\begin{array}{l}-0.6 \\
(0.8)\end{array}$} & $0.97 *$ & $0.56^{*}$ & $4.5^{*}$ & $3.7^{*}$ & $1.2^{*}$ & $1.5 * *$ \\
\hline & & & & & (L1) & (L1) & (L2) & (L2) & (L2) & (L2) \\
\hline & & & & & (5.6) & (2.9) & (9.8) & (5.3) & (2.35) & $(2.0)$ \\
\hline
\end{tabular}

\begin{tabular}{|c|c|c|c|c|c|c|c|c|c|c|}
\hline & \multicolumn{2}{|c|}{ CIIU 33} & \multicolumn{2}{|c|}{ CIIU 341} & \multicolumn{2}{|c|}{ CIIU 355} & \multicolumn{2}{|c|}{ CIIU 384} & \multicolumn{2}{|c|}{ CIIU 385} \\
\hline Parámetro & Modelo A & Modelo B & Modelo A & Modelo B & Modelo A & Modelo B & Modelo A & Modelo B & Modelo A & Modelo B \\
\hline \multirow{2}{*}{0} & $18.76^{* * *}$ & $78.7^{*}$ & $-22.7^{*}$ & $-29.3^{*}$ & (212.0 & 33.7 & $-5.5^{*}$ & $-5.7 *$ & $-18.5^{*}$ & $-20.4^{*}$ \\
\hline & $(2.07)$ & (6.8) & (2.8) & (3.8) & (1.5) & (1.3) & (3.9) & (3.7) & (5.4) & $(6.0)$ \\
\hline \multirow{3}{*}{1} & 0.06 & $0.92 *$ & $1.95 *$ & $1.91 *$ & & & $0.42 *$ & $0.5^{*}$ & $0.55 *$ & $0.41 *$ \\
\hline & (10.14) & 34 & 264 & (31) & (L1) & (L1) & & (41) & 038 & 030 \\
\hline & & & & & (2.1) & (2.2) & & & & \\
\hline \multirow{4}{*}{2} & & & & & & & & & $4.59 *$ & $5.1 *$ \\
\hline & $-4.27^{* *}$ & $-16.3^{*}$ & $4.09 *$ & $5.5^{*}$ & -4.0 & -9.4 & $0.91 *$ & $1.2^{*}$ & & \\
\hline & (191) & $(68)$ & $(322)$ & (43) & $(170)$ & 14 & 00 & $(109)$ & & (L) \\
\hline & & & & & & & & & (6.44) & (6.5) \\
\hline & $1.12 *$ & $-0.7 * *$ & & & $1.41 *$ & $1.5 *$ & $1.05^{*}$ & $0.7^{*}$ & & \\
\hline & (3.5) & $(1.8)$ & & & (2.7) & (2.3) & (3.2) & (2.7) & & \\
\hline
\end{tabular}

*Implica que el coeficiente es significativo al 5\%,** al 10\%. 


\section{APÉNDICE II: DEFINICIONESY FUENTES DE INFORMACIÓN.}

Las fuentes de información utilizadas fueron Mexicanas, de los Estados Unidos y de organismos internacionales. Las fuentes de México son:

- Instituto Nacional de Estadística, G eografía e Informática (INEG I),

- Banco de Mexico (BdM).

En el caso de E.U.A. las fuentes fueron dos publicaciones del U.S. D epartment of Commerce:

- The Statistical Abstract of the US

- The Survey of Current Business.

Las publicaciones de organismos internacionales utilizadas son:

- $\quad$ O.E.C.D. Industrial Structure Statistics, varios años.

- $\quad$ O.E.C.D. The O.E.C.D. Stan D atabase, 1970-1991.

- U.N.I.D .O Industrial Statistics D atabase 1994. 3-Digit level of ISIC Code.

Las actividades manufactureras consideradas en el presente estudio corresponden a la definición convencional de las estadísticas industriales internacionales agrupadas en la Clasificación Internacional Industrial Uniforme (C.I.I.U.). Esta clasificación incluye a los alimentos, las bebidas, textiles y prendas de vestir, cuero y calzado, madera y sus productos, papel y sus productos, químicos y productos relacionados, plásticos y hule, minerales no metálicos (vidrio, porcelana, cemento, etc.), hierro y acero, metales no ferrosos, productos de metal, maquinaria eléctrica y no eléctrica, equipo de transporte, equipo de medición y fotografía.

Definiciones y fuentes de información:

Para cada sector manufacturero se obtuvo la siguiente información.

$\mathrm{X}$ : Volumen de exportaciones. Es el valor de exportación en dólares corrientes (BdM), dividido por WP.

WP: World price index. Precios al productor en Estado Unidos (US. D epartment of Commerce).

PDE: Precios al productor en México en dólares. Es el índice de precios al productor en México (INEG I y BdM) dividido por el índice del tipo de cambio nominal (pesos por dólar) (BdM).

IMP: Índice de producción manufacturera (INEGI.).

MUS: Índice de las importaciones reales de E.U.A. Las importaciones de E.U.A. (O.E.C.D.) divididas por WP.

RULC (RWL y ROL) Costos unitarios relativos de la mano de obra. (U.N.I.D .O.).

Con la excepción de X el periodo para el que se obtuvo la información es 1970-1994. Las estadísticas disponibles no permitieron el desglose de las exportaciones para todos los sectores para el periodo 1970-1980. 


\section{BIBLIOGRAFIA}

Anderton, R. and Dunnet, A. (1987). 'Modelling the behaviour of export volumes of manufactures: an evaluation of the performance of different measures of international competitiveness', in National InstituteEconomicReview A ugust.

Athukorala, P. y Riedel, J.(1991). The small country assumption: a reassessment with evidence from Korea'. Wetuintshaftlidhes-Ardiv, vol.127 (1).

Balassa, B., E. Voloudakis, P. Fylaktos y S.T.Suh (1989). The determinants of export supply and demand in two developing countries: G reece and Korea.' Intemational EconomicJaumal, vol. 3, Num. 1.

Banerjee, A., J. Dolado, J. Hendry (1986). 'Exploring equilibrium relationships through static models: some Monte Carlo evidence' OxfardBullein of Econamicsand Statistis, vol. 48. pp. 253-277.

Buffie, E.F. (1986). 'D evaluation and imported inputs: the large economy case.' Intemational Economic Review, vol. 27. núm.1. Feb. pp. 123-140.

Casar, J.I. (1991). 'La competitividad en la industria manufacturera Mexicana: 1980-1990.' Mimeo. I.L.E.T.

Cohen, A. (1993). 'Efectos de la liberalizacion comercial en las exportaciones.' In: Mexica Auge cisis yajuste (eds. C. Bazdresch, N. Bucay, S. Loaeza y N. Lustig). El Trimestre Economico, Serie de Lecturas 73. F.C.E. vol. 3. 347-371.

Dunlevy, J. (1980). 'A test for the capacity pressure hypothesis within a simultaneous equations model of export performance.' TheReviewof Economics and Statistics, vol. 62.

Enoch, C.A. (1978). 'Measures of competitiveness in international trade.' Bark of Engand Quartery Bullein, vol. 18. pp. 181-195.

Fagerberg, J. (1988). 'International Competitiveness.' EconamicJaumal, vol. 98, June, pp. 355-374.

Faini, R., Clavijo F. y Senhadji-Semlali, A.(1992). 'The fallacy of composition argument. Is it relevant for LD Cs' manufactures exports?.' EuropennEconomicRexiew. pp. 865-882.

Goldstein, M. y M. Khan. (1978). 'The supply and demand factors: a simultaneous approach.' The Reviewof Ecommisand Statistics vol. 60. May, pp. 275-86.

Goldstein, M. y M. Khan. (1985). 'Income and Price effects in foreign trade.' Handbook of Intemational Economics Vol.II, cap.20.

Graf, J.P. (1995). 'Comportamiento de los precios de exportación de productos manufacturados: México, 1980-1995'. Banco de México. D ocumento de Investigación No. 9505. Agosto.

G reene, W.H. (1993). EconmenicAmalysis Macmillan Publishing Company, 2nd. edition.

Greenhalgh, C. (1990). 'Innovation and trade performance of the United Kingdom.' EconmicJamal, 100. (Conference).

Holly, S. y K. Wade (1991). 'UK exports of manufactures: the role of supply side factors.' Scattish Jaunal of Pditical Ecommy. Vol. 38, No.1, February.

Hooper, P. y E. Vrankovich. (1995). International coparisons of the levels of unit labor costs in manufacturing' Board of Governors of the Federal Reserve System. International Finance Discussion Papers. Num. 527, O ctober. 
Krugman, P. (1989). 'Income elasticities and real exchange rates'. European EconomicReviev Vol. 33. May 1031-1054.

Landesmann, M. y A. Snell. (1989). The consequences of Mrs. Thatcher for UK manufacturing exports.' EconamicJaumal. 99.

Lee, K.C., M.H. Pesaran y R.G. Pierse. (1990). Testing for aggregation bias in linear models.' EconamicJamal. Vol. 100 (Conference), pp. 137-150.

Marsh, I.W. y S.P. Tokarick (1994). 'Competitiveness Indicators: a theoretical and empirical assessment'. I.M.F. Working paper, num. 94/ 29. Washington.

Moran, C. (1988). 'A Structural Model for D eveloping Countries Manufactured Exports.' WoddBank EconomicRevien Vol.2, Num. 3.

Muscatelli, V. A. (1994). 'D emand and supply factors in the determination of NIE exports: a reply' EconamicJamal. Vol. 104, November, 1411-1414.

Muscatelli, A., Srinivasan, T.G. y Vines, D. (1994). 'The Empirical Modelling of NIE exports: an evaluation of different approaches.' Jamal of Dedepment Studies vol. 30 (2), pp. 279-302.

Muscatelli, V. A. (1991). Why Hong Kong is not a small country after all: an application of cointegration analysis to a simultaneous model of export demand and supply.' University of Glasgow, Discussion Papers in Economics.

Nguyen, D.T. (1989). 'The demand for LDC exports of manufactures: estimates for Hong Kong. A comment.' EconamicJaumal, Vol. 99. June.

Peñaloza, R. y M. Voljc. (1989). 'Politicas de fomento a las exportaciones.' ComerioExteriar. 39(8).

Riedel, J. (1988). The demand for LDC exports of manufactures: estimates from Hong Kong.' EconomicJaumal, 98. March.

Riveros, L. A. (1992). 'Labor Costs and Manufactured Exports in Developing Countries: an econometric analysis.' WoddDeddqument. Vol. 20. No. 7.

Salas, J. y Alfaro, S.(1992). 'Evolucion de la Balanza comercial del sector privado en Mexico: evaluación de un modelo econometrico.' TrimetreEconómica Vol. 59(4). No. 236.

Thirlwall, A. P. (1979). The Balance of Payments Constraint as an Explanation of International Growth Rate Differences.' Banca Nazionaledd LavoroQuartely Review. March.

UNCTAD . (1991). TradeandDeddpment Repat United Nations. Geneva.

Winters, A. (1981). An economtricmodd of theUKexpat setor. Cambridge. C.U.P.

Winters, A. (1992). Intemational Economics.Macmillan Press. 4th. ed. 